\title{
Linking Parent-Child and Peer Relationship Quality to Empathy in Adolescence: A Multilevel Meta-Analysis
}

\author{
Savannah Boele $\mathbb{C}^{1} \cdot$ Jolien Van der Graaff ${ }^{2} \cdot$ Minet de Wied ${ }^{2} \cdot$ Inge E. Van der Valk ${ }^{2}$ Elisabetta Crocetti $^{3}$. \\ Susan Branje ${ }^{2}$
}

Received: 27 November 2018 / Accepted: 6 February 2019 / Published online: 27 February 2019

(C) The Author(s) 2019

\begin{abstract}
Empathy, which is the ability to feel concern for and to understand others' feelings, is thought to develop in high quality relationships with parent and peers, but also to facilitate the quality of these relationships. While a wide literature has addressed this aspect, the heterogeneity of primary studies, in which different indicators of relationship quality (e.g., support, conflict) and empathy (i.e., affective and cognitive) have been examined, makes it difficult to draw conclusive answers. Therefore, it remained ambiguous how parent-child and peer relationship quality are associated with adolescents' empathy. In order to increase the understanding of these associations, a multilevel meta-analysis was performed, which allowed for including multiple effect sizes from each study. By a systematic literate search, 70 eligible studies were found that provided 390 effect sizes from 75 independent samples. The results showed a small positive correlation between parent-child relationship quality and empathy, and a small-to-moderate positive correlation between peer relationship quality and empathy, which was significantly stronger than the correlation with parent-child relationship quality. Hence, the metaanalytic results indicate that adolescents with higher quality relationships, especially with peers, indeed tend to show more concern for and understanding of others' emotions than adolescents with lower quality relationships. Moreover, the moderation analyses showed stronger correlations for the positive dimension of relationship quality than for the negative dimension, and stronger correlations for composite scores of affective and cognitive empathy than for separate scores of the empathy dimensions. However, no differences in correlations were found between the affective and cognitive empathy dimension, and no moderation effects were found for gender and age. Thus, this meta-analysis demonstrates robust positive associations between parent-child and peer relationship quality and empathy in adolescence, implying that good empathic abilities may be a protective factor for experiencing poor relationships.
\end{abstract}

Keywords Relationship quality $\cdot$ Parent-child relationship $\cdot$ Peer relationship $\cdot$ Empathy $\cdot$ Adolescence $\cdot$ Multilevel metaanalysis

Supplementary information The online version of this article (https:// doi.org/10.1007/s10964-019-00993-5) contains supplementary material, which is available to authorized users.

Savannah Boele

s.boele@tilburguniversity.edu

1 Department of Developmental Psychology, Tilburg University, Tilburg, Netherlands

2 Research Centre Adolescent Development, Utrecht University, Utrecht, Netherlands

3 Department of Psychology, Alma Mater Studiorum University of Bologna, Bologna, Italy

\section{Introduction}

Relationship quality and empathy are thought to be closely related in adolescence. High relationship quality is considered essential for the socialization of empathy, which can occur through the modeling of warm and supportive behavior (Barnett 1987; Eisenberg et al. 2003). Reversely, empathy may foster the quality of adolescents' relationships, as a higher ability to share and understand others' emotions is related to more prosocial and less aggressive behavior towards others (Eisenberg et al. 2010) and better conflict resolution strategies (e.g., de Wied et al. 2007). Nonetheless, there still exists some uncertainty about the association between relationship quality and empathy in adolescence, because of the variation in research design and 
inconsistencies in results of empirical studies on this topic thus far. Therefore, this meta-analysis examined concurrent correlations between adolescent relationship quality and empathy in community samples. Relationship quality with parents and peers were separately examined and moderation analyses were conducted to explain differences in strengths of correlations between studies.

\section{Relationship Quality and Empathy}

\section{Defining empathy}

Empathy is a multidimensional construct that involves other-oriented affective and cognitive responses to another person's emotions. Affective empathy includes sharing similar emotions (emotional contagion) or feeling sorrow or concern for the observed other (empathic concern). Cognitive empathy refers to the understanding of another person's feelings, for example through perspective taking or mentalizing processes (Davis 1983). Affective and cognitive empathy are related (e.g., Jolliffe and Farrington 2006; Van der Graaff et al. 2018), indicating that individuals with a better understanding of other's emotions are likely to also experience more shared feelings or empathic concern. Indeed, it is understood that both responses are needed to enable empathic behavioral responses to others, such as offering comfort (Davis 1983). Although they are connected, affective and cognitive empathy are also distinct processes (Decety and Jackson 2004), and previous research revealed different associations with social functioning (e.g., Batanova and Loukas 2011; Van der Graaff et al. 2018). Thus, although affective and cognitive empathy are conceptually and empirically interrelated, they also tap into different aspects of empathy, and it is important to examine their effects separately, as associations with relationship quality may be different. It was therefore assessed how parent-child and peer relationship quality were uniquely associated with affective and cognitive empathy, as well as how parent-child and peer relationship quality were associated with a combination of both.

\section{Socialization of empathy}

Parents are considered to have an important role in the socialization of empathy (Hoffman 2000). According to the social learning perspective, warm and supportive parents model empathy because they consider their child's perspective and show concern for their emotions (Barnett 1987). The attachment theory posits that warm and supportive parenting satisfies children's emotional needs, which can lead to less preoccupation with one's own emotions and therefore a better ability to attend to the other person's emotions (Bowlby 1982). Moreover, negative parent-child interaction, such as parental hostility and parent-child conflicts, might impede children's emotional regulation skills and hence may hinder perspective taking and showing concern for others (Morris et al. 2007). Although evidence for the role of parents in empathy development comes mainly from studies in childhood, these parental socialization processes are thought to still take place in adolescence.

Importantly, socialization through peer relationships should also be considered, as adolescents become more independent from their parents and spend increasingly more time with peers (Smetana et al. 2006). As peer relationships are particularly characterized by high levels of equality, intimacy, and trust (Youniss and Smollar 1985), the high frequency of intimate interactions provide ample opportunities to observe and model warm and supportive behavior, which may facilitate the development of affective empathy. However, interactions with peers are thought to be essential for specifically the development of cognitive empathy. That is, through reciprocal sharing of thoughts and feelings, disagreements between peers are assumed to facilitate the ability to take others' point of view (Selman 1980), a capability that is still developing in adolescence (Van der Graaff et al. 2014).

Although parental socialization of empathy is expected to continue in adolescence, the contribution of peer socialization on adolescents' empathy development empathy might be larger. An important difference between the relationships is that adolescents form new, voluntary peer relationships, which is in contrast to their permanent, involuntary relationship with their parents (Laursen and Bukowski 1997), and which makes it more necessary for adolescents to understand their peer's perspective. Peer relationships are also more horizontal than parentadolescent relationships, with more egalitarian interactions that are thought to facilitate perspective taking (Selman 1980). Relatedly, during adolescence, parent-child relationships temporarily become less supportive (De Goede et al. 2009a), whereas peer relationships become more supportive (De Goede et al. 2009b). Additionally, in general, peer relationships are more intimate and reciprocal than parent-child relationships (Laursen and Bukowski 1997), and hence co-rumination about each other's problems is a typical aspect of close peer relationships (Rose 2002). Thus, having frequent reciprocal, intimate, and supportive interactions with like-minded persons is considered to be an important ingredient in the development of empathy (Selman 1980; Youniss 1980).

\section{Role of empathy in relationships}

While socialization theories provide the most common background for the association between relationship quality and empathy, it is likely that one's ability for empathy also 
affects the quality of relationships with others. When persons can share and understand feelings of others, it allows them to meet others' needs - thus, permitting them to be supportive and to solve conflicts with compromises. Indeed, the results of prior research suggest that higher levels of empathy predicted more supportive relationships with parents (Miklikowska et al. 2011) and peers (Smith and Rose 2011), and better problem solving capacities in conflicts with parents (Van Lissa et al. 2016). When comparing parent-child and peer relationships, empathy may be particularly important to gain and maintain high quality relationships with peers. Despite average changes in interaction patterns between children and parents during adolescence (Furman and Buhrmester 1992; Larson and Richards 1991), the quality of the parent-child relationship remains relatively continuous, as it is an accumulation of previous experiences in childhood (Laursen et al. 2010). Relationships with peers, however, are being formed and increasingly fulfill functions of closeness, supportiveness, and intimacy during adolescence (Furman and Buhrmester 1992; Larson and Richards 1991). Thus, it was expected that adolescents with high levels of empathy have high quality relationships, particularly with peers.

\section{The Need for a Meta-Analysis}

Even though the theoretical background implies a positive association between adolescent relationship quality and empathy, a meta-analysis is needed for several reasons. First, empirical results show inconsistencies. For example, different correlations have been reported for boys and girls (e.g., Adams et al. 1982; Heller et al. 2007), for affective and cognitive empathy (Li et al. 2015; Meuwese et al. 2017), and between different informants for relationship quality (Soenens et al. 2007). Second, researchers have examined relationship quality with a divers set of indicators, ranging from overall quality (Smith and Rose 2011) and satisfaction (Haugen et al. 2008; Sillars et al. 2005), to specific indicators, such as support (de Kemp et al. 2007), open communication (Heller et al. 2007), and conflict frequency (Van Lissa et al. 2015). Given the empirical inconsistencies and variation in research designs, a meta-analysis can present a better overview by providing an overall correlation and by considering potential moderators to increase the understanding of the heterogeneity among results of previous studies.

\section{Dimension of relationship quality}

A distinction was made between the positive (e.g., support) and negative dimension (e.g., conflict) of relationship quality to test whether they were differently related to empathy in adolescence. With respect to parent-child relationship quality, a positive association between the positive dimension of relationship quality and empathy was expected. However, concerning the negative dimension of parent-child relationship quality, it was expected that the association with empathy could go in both directions. On the one hand, more frequent conflicts with parents in which parents explain their point of view might enhance perspective-taking abilities, and therefore adolescents with more parent-child conflicts may score higher on empathy, resulting in a positive association. On the other hand, adolescents with better perspective taking abilities might have less conflicts with their parents or might be less likely to show maladaptive conflicts resolution styles, because they have a better understanding of the emotions of their parents and can respond more empathically (Eisenberg et al. 2010), which would result in a negative association.

Concerning peer relationship quality, a positive association was expected between the positive dimension of relationship quality and empathy, and the direction of the association with the negative dimension of peer relationship quality can also be theorized in both directions. First, (higher frequency of) peer conflicts can be positively associated with empathy, as disagreements between peers are thought to actually facilitate perspective taking because of reciprocal sharing of perspectives (Selman 1980; Youniss 1980). Second, peer conflicts and in particular poor conflict resolution strategies can be negatively associated with empathy, because higher perspective taking may facilitate constructive conflict solving (De Wied et al. 2007), and because strong negative emotions might be so overwhelming that they prevent the adolescent to attend to the perspective of the other.

\section{Dimension of empathy}

Even though affective and cognitive empathy are seen as conceptually and empirically related (Decety and Jackson 2004; Van der Graaff et al. 2018), different associations with parent-child and peer relationship quality can be expected based on socialization theories. That is, parental socialization theories specifically highlight the important role of parental warmth and support in the development of affective empathy (Hoffman 2000), whereas theories about peer socialization place more emphasis on the role of reciprocity and mutual understanding between peers in the development of perspective taking (Selman 1980). Therefore, it was expected that parent-child relationship quality is more strongly associated with affective empathy than to cognitive empathy, and peer relationship quality is more strongly associated with cognitive empathy than to affective empathy.

\section{Type of relationship}

With respect to the parent-child relationship, it has been suggested that the role of fathers in children's prosocial 
development is less substantial than the role of mothers, as fathers have less opportunities to reinforce and support children's prosocial development, because they spend less time with their children (Yeung et al. 2001), and are less aware of their children's prosocial behavior (Hastings et al. 2007). However, there is also evidence indicating that fathers are more involved in the socialization of cognitive empathy and mothers in affective empathy (Miklikowska et al. 2011). To clarify this, it was examined whether mother- and father-relationship quality are differently related to adolescent cognitive and affective empathy.

Regarding peer relationships, a distinction was made between quality of relationships between friends, romantic partners, and siblings. Socialization influences in these relationships can vary in strength, because friendships and romantic relationships are voluntary and mainly based on equality and reciprocity, whereas sibling relationships are involuntary and may be less equal and reciprocal due to age differences (Laursen and Bukowski 1997). Hence, it was expected that the association of empathy with friendship and romantic relationship quality is stronger than the association of empathy with sibling relationship quality.

\section{Age}

It was examined whether the correlation between relationship quality and empathy varied as a function of age. As adolescents gain more independence from their parents and spend less time with them (Smetana et al. 2006), it was expected that the association between parent-child relationship quality and adolescents' empathy is stronger for younger than older adolescents. In contrast, because time spent with peers and intimacy between peers increases during adolescence (Buhrmester and Furman 1987; Larson and Richards 1991), it was expected that the association between peer relationship quality and empathy is stronger for older than younger adolescents.

\section{Gender}

Gender differences were expected in the correlations, as parents might socialize girls and boys differently according to gender role expectations (e.g., girls are expected to be more affectionate and caring than boys) (Bem 1981; Kennedy Root and Denham 2010). Especially in adolescence, when puberty sets in and physical gender differences become apparent, gender stereotypical behavior might be more reinforced within the parent-child relationship. Hence, parents might act as better empathic models for and encourage more empathic behavior in adolescent girls than boys. Furthermore, within peer relationships, girls tend to focus more on cooperation, whereas boys focus more on status and competition (Rose and Rudolph 2006).
Therefore, the positive loop between peer relationship quality and empathy might be stronger for girls than boys, because higher levels of empathy in girls are likely to promote more cooperation and mutual support, and vice versa. Thus, it was expected that the correlation of both parent-child and peer relationship quality with empathy is stronger for girls than for boys, particularly regarding affective empathy.

\section{Additional sample, study, and measurement characteristics}

In addition to the above-mentioned moderators, the following moderators without specific hypotheses were explored: ethnic composition of the sample, publication year, reliability of measures, informants, and assessment method.

\section{The Present Study}

The aim of the present study is to increase the understanding of how parent-child and peer relationship quality are related to empathy in adolescence, because empirical studies vary in their research designs (e.g., cognitive versus affective empathy, support versus conflict), and because to date, no synthetization was available. To this aim, concurrent correlations of adolescent parent-child and peer relationship quality with empathy in a community population were assessed with meta-analytic models. Based on socialization theories (Hoffman 2000) and the implication that empathy fosters high quality interaction (e.g., Van Lissa et al. 2016), positive associations were expected between parent-child and peer relationship quality and empathy in adolescence. Additionally, as peer relationships are considered to play a key role in social development (Youniss 1980), the correlation between peer relationship quality and empathy was expected to be stronger than the correlation between adolescent parent-child relationship quality and empathy. To examine these hypotheses, a multilevel approach was adopted, allowing to include multiple effect sizes from one study or sample (Van den Noortgate et al. 2015). In addition, moderator analyses were conducted to explain inconsistent results available in the literature by showing which factors might amplify or attenuate the concurrent correlations.

\section{Method}

\section{Study Retrieval}

\section{Search strategy}

The initial search was performed in November 2016 and updated in October 2018 and January 2019. Eligible studies 
were searched for in electronic databases: PsycINFO, PsycARTICLES, Psychology and Behavioral Sciences Collection, ERIC, and Web of Science Social Sciences Citation Index (SSCI). The search was constrained to peer-reviewed articles written in English. Studies had to use at least one key word in the title, keywords, and/or abstract for each of the following aspects: (I) relationship quality, (II) type of relationship, (III) empathy, and (IV) adolescents.

I. Key words for overall relationship quality (i.e., "relation* quality" or satisfact*) and parent-child or peer relationship (i.e., "parent-adolescent relation*" or "parent-child relation*" or "friendship" or "peer relation*" or "sibling relation*"). Separate key words were used for the positive dimension (i.e., attach $^{*}$ or bond* or close* or proximity or cohesi* or intima* $^{*}$ or secur* or harmon* or companion* or alliance or cooperat* or affect* or support* or nurtur* or warmth or admiration or trust* or loyal* or communicat" or "positive affect" or "positive interaction" or equal* or egalitarian or symmetric) and negative dimension (i.e., conflict* or disagreement or argue* $^{*}$ or bicker* or fight* or agressi* or hostil* or alienation or "negative affect" or "negative interaction" or inequal* or asymetric or power or dominan* or authorit*).

II. Key words for type of relationship: mother* or maternal or father* or paternal or parent* or family or peer* or friend* or partner* or sibling* or brother or sister or twin or relative.

III. Key words for empathy: empath* or sympath* or "vicarious emotional respond"” or "emotion* contagion" or "theory of mind" or ("compassion" not "self-compassion") or "perspective taking" or "role taking" or mentaliz* or "emotion* recognition").

IV. Key words for adolescence: adolescen* or youth or teen* or "middle school" or "high school" or "secondary school" or "young people".

To exclude studies based on clinical samples a subsequent search string was used: NOT autis* or disorder* or diagnos* or disabilit* or syndrome or disease or illness.

In addition to the database search, references of eligible studies were manually checked in the reference lists of selected studies (i.e., backward citation search) in order to identify articles that were missed in the database search.

\section{Inclusion criteria}

Studies were included when they met the following four criteria. First, the study had to assess overall relationship quality, or indicators of the positive (i.e., warmth and support) or negative dimension (i.e. conflict). Although key words were used for the dimension of power, correlations between indicators of power and empathy were excluded, because indicators of power imbalance within the parentchild relationship overlap with parenting practices (e.g., parental control and monitoring) and are therefore less applicable to peer relationships (Furman 1998). When a composite score of relationship quality also comprised power imbalance, the study was not excluded, but it was coded that the measurement also included power imbalance. Consequently, the effect size with power imbalance was included when calculating the overall correlation but was excluded when correlations were calculated for a specific relationship quality indicator (e.g., warmth, conflict). Moreover, prosocial behavior within relationships was not included as an indicator of the positive dimension, as it is conceptually too closely related to empathy (Eisenberg and Fabes 1990). Furthermore, the aim was to examine the stable quality of the relationship, and thus studies that manipulated relationship quality (e.g., induced conflict situations) were excluded.

Second, the study had to assess relationship quality with parents or peers. Peers could include peers in general (when authors did not further specify what sort of peer it involved, such as friends or classmates), friends, romantic partners, and siblings. Siblings were considered as peers if both siblings were adolescents (age between 10-20 years). Furthermore, studies that examined relationship quality with family members in general were excluded, because this might also include siblings and/or grandparents.

Third, empathy had to be an affective or cognitive response to another person's emotions (or a combination). Affective responses included emotional contagion and empathic concern. Cognitive responses included empathic accuracy, perspective taking, and mentalizing. Hence, personal distress and prosocial behavior were excluded, because personal distress is a self-oriented affective response and prosocial behavior is a behavioral response (Davis 1983).

Fourth, studies had to assess a community sample with mean age between 10 and 20 years old. Clinical samples were excluded, because levels of relationship quality and empathy may be non-normative in such samples.

\section{Study Selection}

The database search resulted in 1158 unique hits. The second author screened $10 \%$ of the hits and showed an acceptable agreement of $\kappa=0.70$ with the first author. Disagreement was solved through discussion and led to improved inclusion and exclusion criteria. Based upon screening of titles and abstracts, the first author retrieved the 
Fig. 1 PRISMA flow diagram of the systematic search. Note. $n=$ number of studies. $k=$ number of correlations

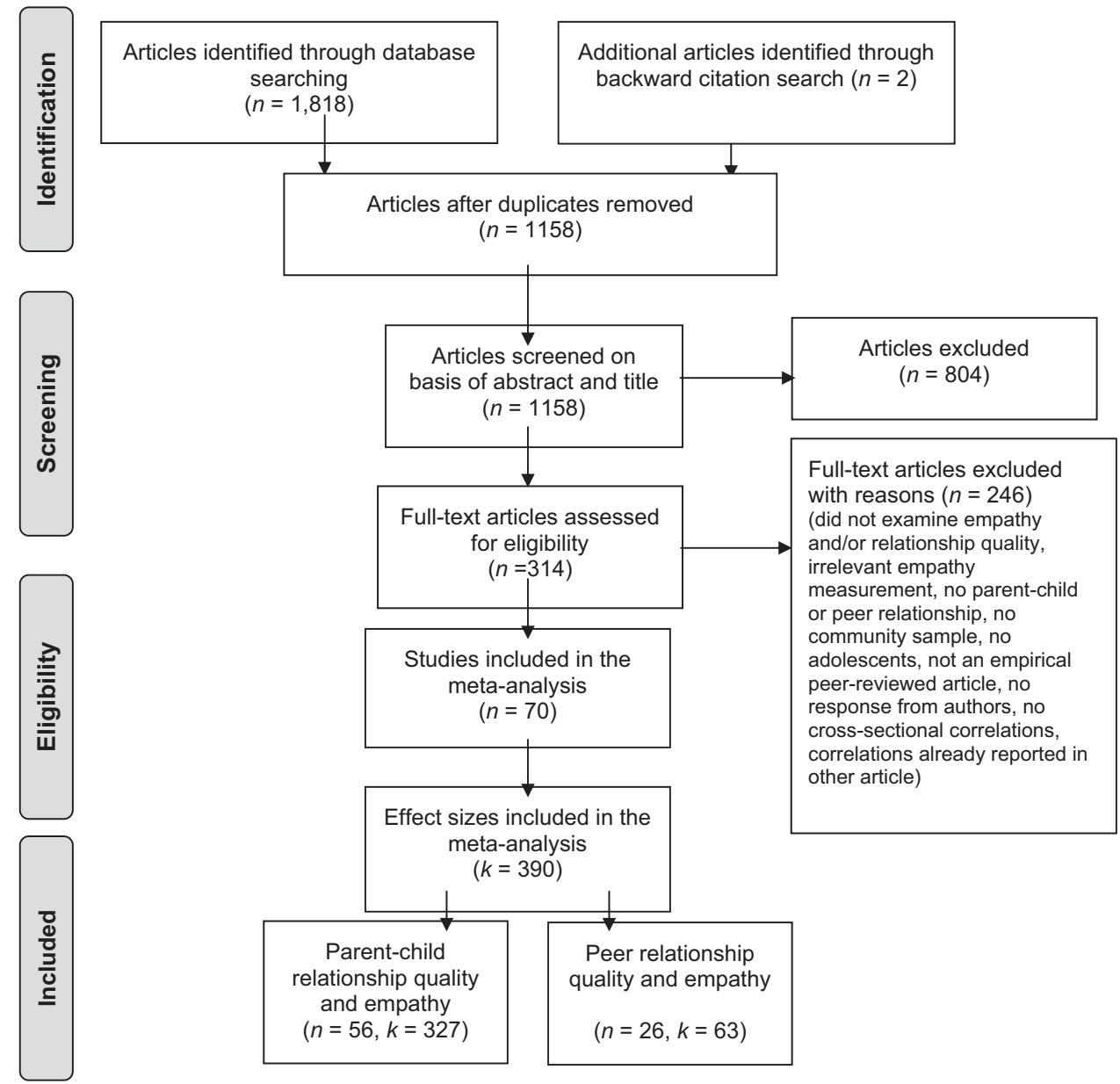

full text of 314 articles, of which 68 articles were included (see Fig. 1 for exclusion reasons). Two additional studies were found by backward citation search. In sum, 70 eligible studies were found. After clustering studies that analyzed the same sample or separating subsamples within studies, 75 independent samples remained, which had combined 390 correlations. Included studies and their characteristics are reported in Table 1.

\section{Coding the Studies}

The coding scheme documented information of the relationship quality indicator, empathy indicator, study and sample characteristics, and correlation(s). The first author coded all studies and the second author coded a subset of 48 correlations (12\%) of 10 studies (14\%). For study characteristics, intercoder reliability was calculated for sample size (ICC $=0.995$ ), mean age $(\mathrm{ICC}=1.0)$, percentage girls $(\mathrm{ICC}=0.99)$, and ethnicity $(\kappa=1.0)$. For effect size characteristics, inter-coder reliability was calculated for dimensions of relationship quality and empathy $(\kappa$ 's $=1.0)$, type of parent-child or peer relationship $(\kappa=0.97)$, and correlation coefficient $(\mathrm{ICC}=0.99)$.

\section{Relationship quality}

First, it was coded whether the study involved parent-child or peer relationship quality, gender of parent (i.e., mother or father), and type of peer relationship (i.e., peers in general, friend, romantic partner, or siblings). Next, indicators were categorized into the positive and negative dimensions of relationship quality. Higher scores on the positive dimension represented higher relationship quality, such as warmth, support, and constructive conflict resolution style. Indicators of the negative dimension included scales where a higher score reflected lower relationship quality, such as hostility, conflict frequency and poor conflict resolution style. In order to conduct moderator analyses on the complete data, the correlations of the negative dimension were reverse coded, such that all correlations indicated that higher relationship quality was related to higher empathy. Last of all, positive relationship indicators were categorized into three (or four) categories: warmth and support, attachment, (friendship quality,) and communication quality. Not enough variation was present to distinguish between categories of negative relationship indicators. 


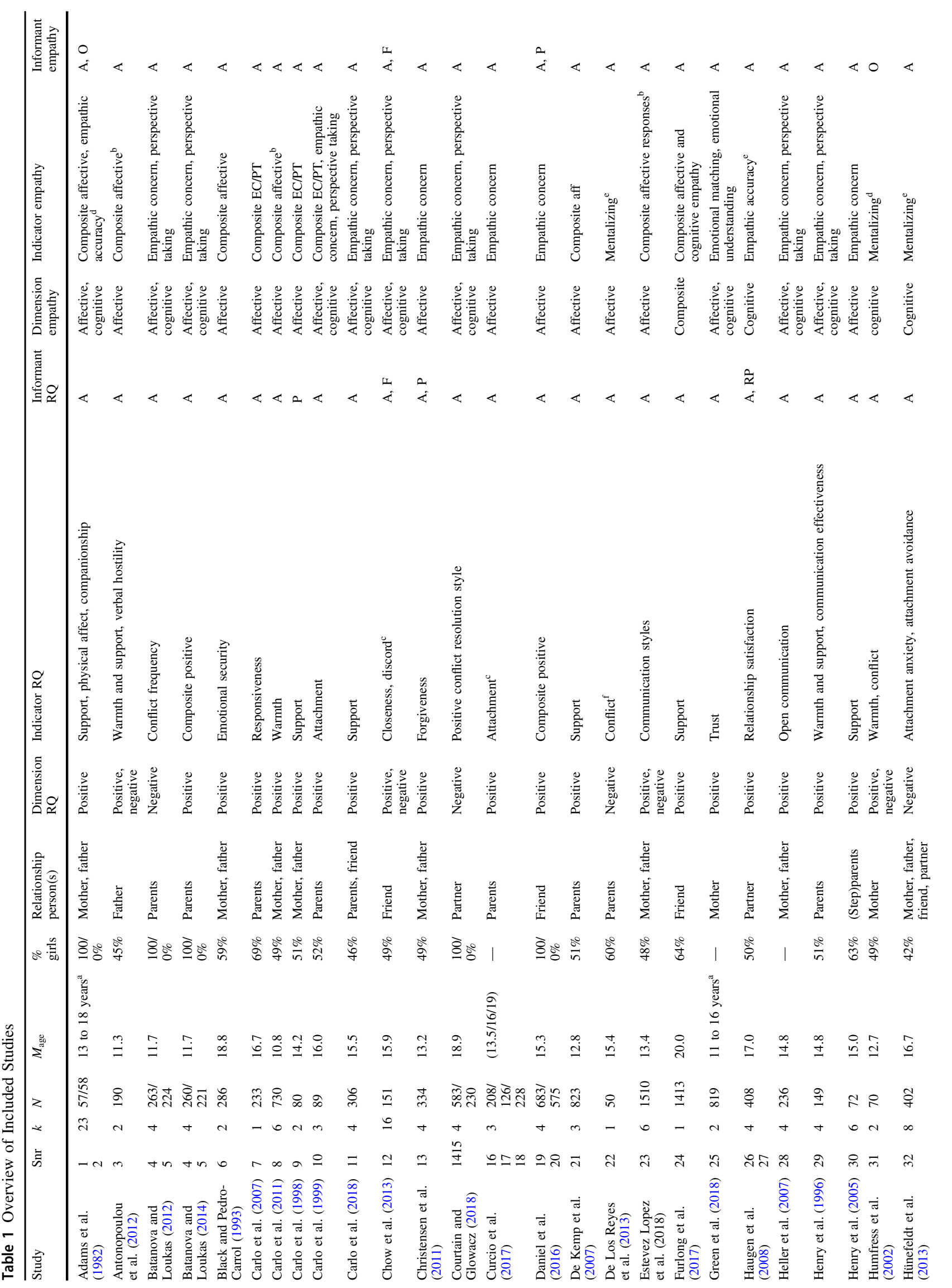




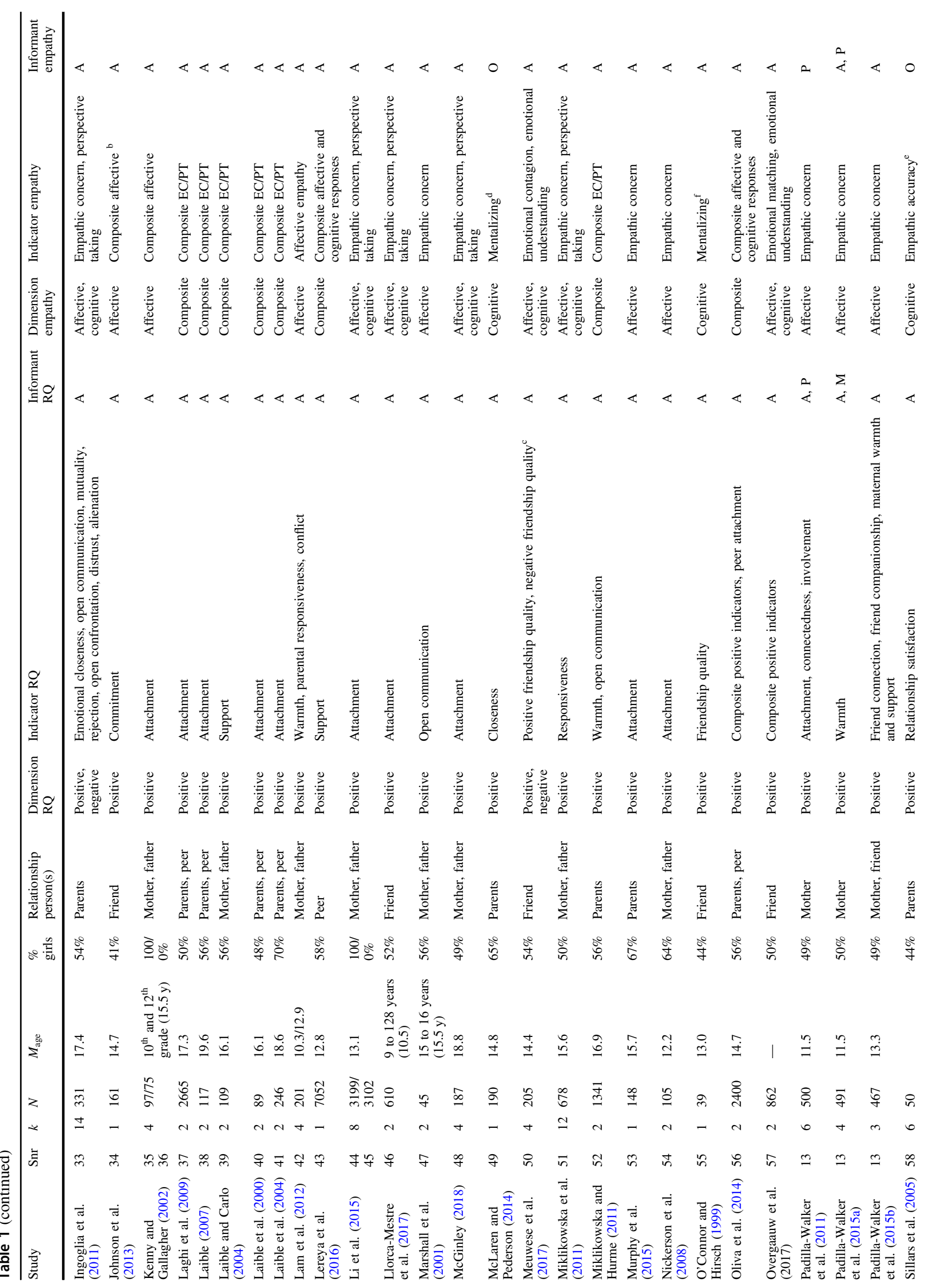




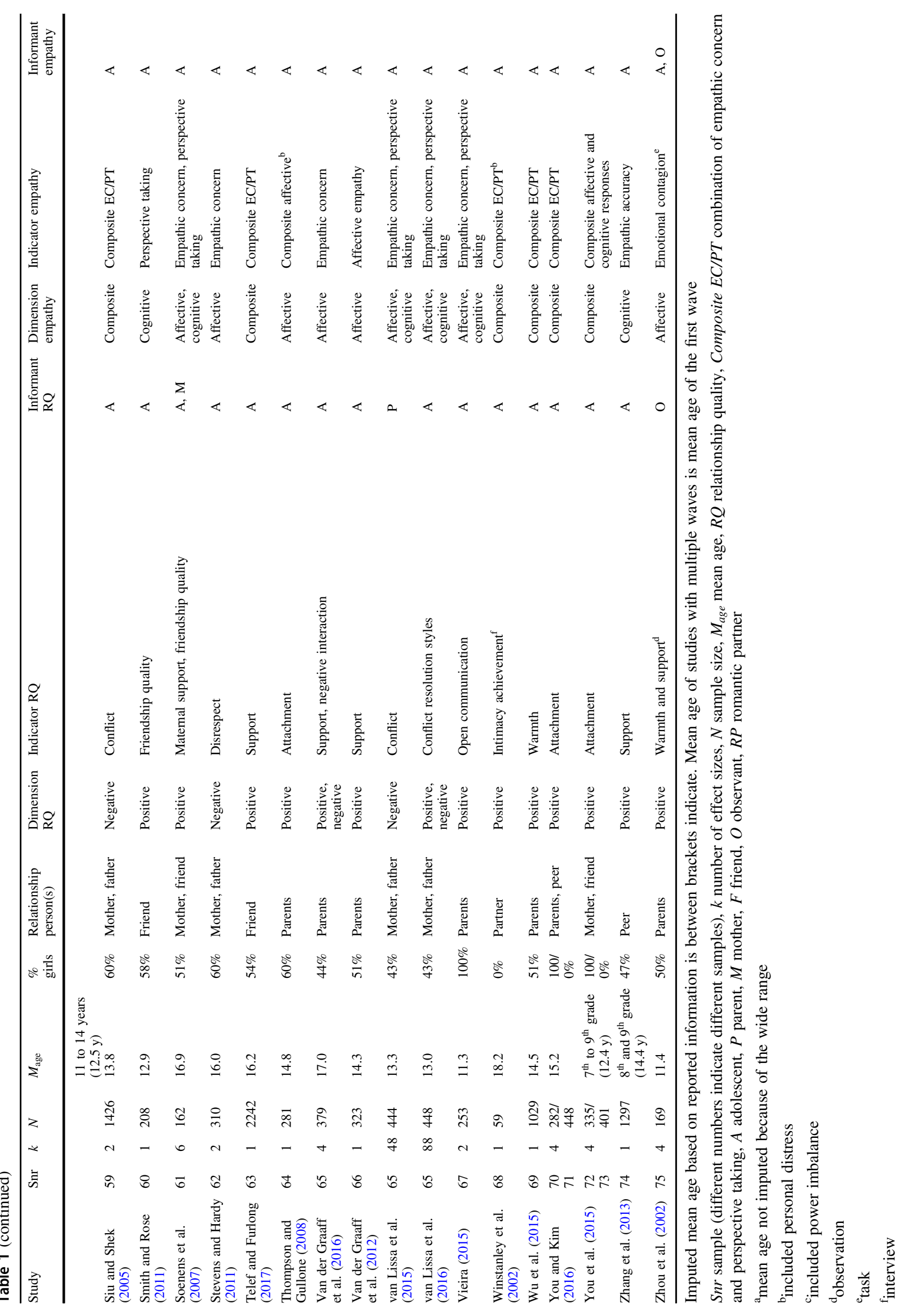


Moreover, assessment method, informant(s), and reliability of the relationship quality measurement were coded. When authors did not report the exact reliability for separate subscales, for example it was not reported for the subscales, the average reliability was coded.

\section{Empathy}

It was coded whether empathy comprised affective empathy, cognitive empathy, or a composite score that included both affective and cognitive empathy (e.g., sympathy). Affective empathy measures were categorized as empathic concern, emotional contagion, or a combination of affective empathy-related responses. Cognitive empathy measures were categorized as perspective taking, empathic accuracy, or mentalizing. Similar to the approach for relationship quality, assessment method, informant(s), and reliability were coded.

\section{Study and sample characteristics}

Regarding study characteristics, publication year, country of leading author, and continent of data collection were coded. Regarding sample characteristics ${ }^{1}$, it was coded whether the sample belonged to a specific research project (to detect double samples), sample size, mean age ${ }^{2}$, gender composition (i.e., percentage of girls), and ethnic composition. Ethnic composition was coded as majority ( $>75 \%$ of participants' ethnicity can be considered to be in the ethnic majority in the country of data collection), minority (i.e., when $>75 \%$ of participants' ethnicity can be regarded as the ethnic minority in the country of data collection), or mixed (i.e., when less than $75 \%$ of the sample were the ethnic majority or minority).

\section{Effect size}

Pearson's product-moment correlation coefficient $r$ was chosen as effect size. A small, moderate, and large effect is indicated by $r=0.10,0.30$, and 0.50 , respectively (Cohen 1992). When authors reported that the correlation was not significant without reporting the exact coefficient, the correlation was coded as zero.

\footnotetext{
${ }^{1}$ Socioeconomic status (SES) was not included as a moderator, because information about SES was too diverse across articles or was lacking, and therefore difficult to compare between studies. Initially, the first and second author coded SES in a subset of articles, but interrater reliability was low, and therefore SES was dropped as a moderator.

${ }^{2}$ When authors only reported the school grades of the participants, a mean age that was likely the mean age of the sample ( 10 years for fifth grade and 17 years for twelfth grade) was calculated. For example, when participants were in the fifth grade (10 years) and sixth grade (11 years), a mean age of 10.5 was attributed.
}

\section{Missing information}

Of three publications, authors did not respond to the e-mail request to send the full text. Therefore, these potential eligible studies could not be included. If essential information (e.g., mean age, or the target correlation) was not reported in a potential eligible study, authors were contacted through email (with two reminders in absence of a response) with a request to send additional information. In total, thirty requests were sent, of which fifteen requests were met. Studies could not be included when authors did not respond on a request for correlational data $(n=13)$.

\section{Statistical Analysis}

\section{Individual effect sizes}

Correlation coefficients were transformed to the normally distributed Fisher's $z$. The Fisher's $z$ score and its variance were used in the meta-analyses, and afterwards back transformed to Pearson's correlation coefficients. Fisher's $z$ scores were transformed to Pearson's correlations with the R package “compute.es” (AC Del Re 2013).

\section{Overall effect sizes and moderators}

A multilevel approach was adopted, which takes into account the hierarchical structure of the dataset, such that effect sizes are nested within studies (Assink and Wibbelink 2016). Hence, a multilevel approach allowed for extracting multiple effect sizes from the same study (e.g., when a study provided separate effect sizes for affective and cognitive empathy) while taking into consideration the dependency between them. Therefore, the multilevel approach ensures that studies with multiple effect sizes do not have a larger influence on the meta-analytic estimates than studies that provided a unique effect size. To control for this dependency, a three-level structure was assigned to the metaanalytic models, which takes into account three different variance components: (1) sampling variance (i.e., variance at the level of the individual effect size), (2) within-study variance (i.e., variance of effect sizes within the same study), and (3) between-study variance (i.e., variance of effect sizes between different studies) (Van den Noortgate et al. 2015).

The statistical analyses were conducted by using the package "metafor" (Viechtbauer 2010) in the statistical software environment R 3.5.0 (R Core Team 2016). Restricted Maximum Likelihood Estimation (REML) was used to reduce bias of variance estimates (Van den Noortgate et al. 2015). First, overall correlations for the associations of parent-child and peer relationship quality with empathy were estimated. Second, heterogeneity in 
correlations within and between studies was tested. To examine heterogeneity within studies (level 2), it was tested whether the three-level model fitted better than a two-level model (i.e., only sampling and between-study variance) as indicated by a significant one-sided log-likelihood-ratio test, showing that variance is present at the second level. Similarly, heterogeneity between studies was tested by examining the fit of the three-level model against a model that only had variance at the first (sampling variance) and second level (within-study variance). By using the procedure formulated by Cheung (2014), the distribution of variance at each level of the model was calculated.

If the results indicated heterogeneity, moderator analyses were conducted to explain it. Variables were tested as moderators when data were available for at least three studies (Crocetti 2016). Significance of moderators was tested with an omnibus test (i.e., the $Q_{\mathrm{m}}$ statistic) (Cheung 2014). Dummy variables were created for categorical moderators and follow up contrasts were examined to analyze differences in correlations between categories.

\section{Publication bias}

The presence of publication bias was examined by funnel plots, which show the relation between sample size and effect size. Funnel plots that imply no publication bias demonstrate symmetrical distributed ESs around the mean ES (Duval and Tweedie 2000). The symmetry of the funnel plot was examined by Eggers regression tests, in which sampling variance was added as a moderator to take into account the dependency between correlations from the same study (Egger et al. 1997). Because the correlation between empathy and the negative dimension of peer relationship quality was only examined in three studies, sampling variance could not be entered as a moderator, and therefore Egger's regression test was performed without it. In case of funnel plot asymmetry, an adjusted correlation by using the "trim-and-fill" method was provided (Duval and Tweedie 2000). In addition to the funnel plots, the statistic Rosenthal's Fail-safe $N$ was calculated, which indicates how many missing studies would be required in order to find a non-significant $(p>0.05)$ correlation (Borenstein et al. 2011; Rosenthal 1979). Data of aggregated correlations at sample level (i.e., correlations averaged within samples) was used to examine the Fail-safe $N$ with independent data.

\section{Results}

\section{Study Sample}

Because only two eligible studies were retrieved that examined sibling relationship quality and empathy, these two studies were excluded from the analyses (Lam et al. 2012; Harper et al. 2016) ${ }^{3}$.

In total, 390 effect sizes (ESs) of 70 studies $(n)$ were retrieved, which included 75 independent samples $\left(n_{s a}\right)$. Specifically, $327 \mathrm{ESs}$ from 57 independent samples $(N=$ $28951^{4}$ ) were retrieved of the association between parentchild relationship quality and empathy, and $63 \mathrm{ESs}$ from 31 independent samples $\left(N=25423^{2}\right)$ of the association between peer relationship quality and empathy.

Concerning the 75 independent samples, sample sizes ranged from 39 to $7052(M=614, S D=1024)$, mean ages from 10.5 to 20.0 years old $(M=15.0, S D=2.3)$, and percentage of girls from $0 \%$ to $100 \%(M=52.4 \%, S D=$ 27.8). Participants were from the continents America $\left(n_{s a}=\right.$ $33)$, Europe $\left(n_{s a}=26\right)$, Asia $\left(n_{s a}=9\right)$, Australia $\left(n_{s a}=1\right)$, Oceania $\left(n_{s a}=1\right)$, a mix of continents $\left(n_{s a}=2\right)$, or unknown $(n=3)$. Of the 70 studies, 37 examined a sample in which the participants were from the ethnic majority. Only three examined samples were mainly composed of ethnic minorities, and 9 studies examined a mixed sample. Fourteen studies did not report on participant ethnicity. The countries of publication were mainly United States $(n=39)$, the Netherlands $(n=7)$, United Kingdom $(n=3)$, Italy $(n=3)$, and China $(n=3)$. Publication year of the studies ranged from 1982 to 2018, with a mean of 2010 and a median of 2012 .

\section{Association between Relationship Quality and Adolescent Empathy}

A small positive correlation of 0.18 (95\% CI [0.15, 0.20], $p<0.001$ ) was found between parent-child relationship quality and empathy, and a small-to-moderate correlation of 0.29 (95\% CI [0.24, 0.33], $p<0.001)$ between peer relationship quality and empathy. With respect to the separate relationship quality dimensions, a small positive correlation with empathy was found for the positive dimension of parent-child relationship quality $(r=0.19,95 \%$ CI $[0.16$, 0.22 ],$p<0.001)$ and a moderate positive correlation for the positive dimension of peer relationship quality $(r=0.31$, $95 \%$ CI $[0.26,0.35], p<0.001)$. Small negative correlations with empathy were found for the negative dimension of

\footnotetext{
$\overline{3}$ Harper et al. (2016) reported significant correlations between sibling affection and affective empathy of 0.22 for boys and 0.29 for girls, and nonsignificant correlations between sibling conflict and affective empathy of -0.01 for both boys and girls. The data of Lam et al. (2012) showed significant correlations between sibling warmth and affective empathy of 0.24 for the youngest siblings and 0.42 for the oldest sibling, and a nonsignificant correlation between sibling conflict and affective empathy of -0.08 for the youngest sibling and a significant correlation of -0.18 for the oldest sibling.

${ }^{4}$ When multiple studies examined the same sample, the size of the largest sample was counted.
} 
parent-child relationship quality $(r=-0.13,95 \%$ CI $[-0.18,-0.07], p<0.001)$ and peer relationship quality $(r=-0.11,95 \%$ CI $[-0.17,-0.06], p<0.001)$. Moreover, the overall correlation with peer relationship quality was significantly stronger than the correlation with parent-child relationship quality, $F(1,388)=13.74, p<0.001$.

\section{Test of Heterogeneity}

Concerning the correlation between parent-child relationship quality and empathy, the significant $Q$-statistic ( $Q$ $(326)=2197.46, p<0.001)$ suggested variance between correlations. Constraining the within-study variance $\left(\chi^{2}(1)=512.17, p<0.001\right)$ and the between-study variance to zero $\left(\chi^{2}(1)=43.69, p<0.001\right)$ resulted in a deteriorated model fit, suggesting that the variances deviated from zero. The distribution of variance across the three levels was: $14.6 \%$ (sampling variance), 53.6\% (within-study variance), and $31.8 \%$ (between-study variance).

There was also significant variance between correlations for peer relationship quality and empathy $(Q(62)=$ 1023.52, $p<0.001)$. Constraining the variances within studies $\left(\chi^{2}(1)=50.50, p<0.001\right)$ and between studies to zero $\left(\chi^{2}(1)=7.06, p=0.008\right)$ resulted in worse model fits, indicating that the variances differed significantly from zero. The distribution of variance across the three levels was: $2.0 \%$ (sampling variance), $44.1 \%$ (within-study variance), and $54.0 \%$ (between-study variance).

\section{Moderator Analyses}

Results of the moderator analyses are reported in Table 2 (for parent-child relationship quality) and Table 3 (for peer relationship quality). In the tables, the number of effect sizes $(k)$, number of samples $\left(n_{\mathrm{sa}}\right)$, correlation coefficient $(r)$ or slope, and the statistic of the moderator test $\left(Q_{\mathrm{m}}\right)$ with its $p$-value are reported.

\section{Relationship dimension}

For both parent-child $(F(1,325)=120.13, p<0.001)$ and peer relationship quality $(F(1,61)=13.90, p<0.001)$, relationship quality dimension was a significant moderator, such that correlations with empathy were stronger for the positive dimensions of relationship quality compared to the negative dimension.

Correlations for separate indicators of the positive dimension (warmth vs. attachment vs. quality of communication/friendship quality) were not significantly different from each other for both parent-child $(F(2,177)=0.21$, $p=0.812)$ and peer relationship quality $(F(2,18)=0.31$, $p=0.738)$.

\section{Empathy dimension}

For both parent-child $(F(2,324)=3.71, p=0.026)$ and peer relationship quality $(F(2,60)=6.32, p=0.003)$, empathy dimension was a significant moderator. Follow up contrasts suggested that a composite score of affective and cognitive empathy was more strongly correlated to parentchild relationship quality than a separate score affective empathy (not cognitive empathy). Peer relationship quality was most strongly correlated to a composite score of affective and cognitive empathy then separate scores of both affective and cognitive empathy.

Specific indicator of empathy (e.g., empathic concern, perspective taking, mentalizing) did not moderate the correlation with parent-child relationship quality $(F(4,277)=$ 2.20, $p=0.069)$ but did moderate the correlation with peer relationship quality $(F(2,42)=5.88, p=0.006)$. However, follow up contrasts indicated a stronger correlation between parent-child relationship quality and a composite score of empathic concern and perspective taking compared to a separate score of empathic concern. For peer relationship quality, a stronger correlation was found with a composite score of empathic concern and perspective taking compared to separate scores of empathic concern or perspective taking.

\section{Type of relationship}

Type of relationship (parents vs. mother vs. father, or peer vs. friend vs. romantic partner) moderated the correlation with parent-child relationship quality $(F(2,324)=5.89$, $p=0.003)$ but not the correlation with peer relationship quality $(F(2,60)=2.38, p=0.101)$. Follow up contrasts indicated that the correlation of empathy was stronger with parent-child or mother-child relationship quality compared to father-child relationship quality.

\section{Age and gender}

Age and gender did not significantly moderate the correlations of empathy with parent-child (age: $F(1,300)=0.00$, $p=0.997$; gender: $F(1,312)=0.35, p=0.553)$ and peer relationship quality (age: $F(1,59)=3.91, p=0.053$; gender: $F(1,61)=0.01, p=0.907)$.

\section{Additional sample, study, and measurement characteristics}

With respect to ethnic composition (majority vs. minority vs. mixed), a significant moderation effect was found for the correlation between peer relationship quality and empathy $(F(2,41)=5.13, p=0.010)$, but not for the correlation between parent-child relationship quality and empathy ( $F$ $(1,275)=0.41, p=0.523)$. The results of the contrast 
Table 2 Results of the Association between Parent-Child Relationship Quality and Empathy

\begin{tabular}{|c|c|c|c|c|c|c|c|}
\hline \multirow[t]{2}{*}{ Variable } & \multirow[t]{2}{*}{$k$} & \multirow[t]{2}{*}{$n_{\mathrm{sa}}$} & \multirow[t]{2}{*}{$r /$ slope } & \multicolumn{2}{|c|}{$95 \% \mathrm{CI}$} & \multirow[t]{2}{*}{$Q_{\mathrm{M}}$} & \multirow[t]{2}{*}{$p$-value } \\
\hline & & & & Lower & Upper & & \\
\hline Overall correlation & 327 & 57 & $0.18 * * *$ & 0.15 & 0.20 & & \\
\hline \multicolumn{8}{|l|}{ Moderator analyses } \\
\hline \multicolumn{8}{|l|}{ Dimensions } \\
\hline Dimension RQ & 327 & 57 & & & & $\begin{array}{l}F(1,325)= \\
120.13\end{array}$ & $<0.001$ \\
\hline Positive & 186 & 53 & $0.20^{\mathrm{a} * * *}$ & 0.18 & 0.23 & & \\
\hline Negative (reverse coded) & 141 & 10 & $0.05^{\mathrm{b} * *}$ & 0.01 & 0.08 & & \\
\hline Positive indicator RQ & 180 & 48 & & & & $F(2,177)=0.21$ & 0.812 \\
\hline Warmth & 100 & 25 & $0.20 * * *$ & 0.16 & 0.24 & & \\
\hline Attachment & 35 & 19 & $0.20 * * *$ & 0.15 & 0.25 & & \\
\hline Quality of communication & 45 & 9 & $0.18 * * *$ & 0.12 & 0.24 & & \\
\hline Dimension empathy & 327 & 57 & & & & $F(2,324)=3.71$ & 0.026 \\
\hline Affective & 181 & 37 & $0.16^{\mathrm{a} * * *}$ & 0.13 & 0.18 & & \\
\hline Cognitive & 126 & 22 & $0.17^{\mathrm{ab} * * *}$ & 0.14 & 0.21 & & \\
\hline Composite & 20 & 15 & $0.24^{\mathrm{b} * * *}$ & 0.18 & 0.29 & & \\
\hline Indicator empathy & 282 & 47 & & & & $F(4,277)=2.20$ & 0.069 \\
\hline Empathic concern & 132 & 21 & $0.17^{\mathrm{a} * * *}$ & 0.13 & 0.21 & & \\
\hline Composite affective & 22 & 7 & $0.17^{\mathrm{ab} * * *}$ & 0.10 & 0.24 & & \\
\hline Mentalizing & 8 & 3 & $0.11^{\mathrm{ab} *}$ & 0.00 & 0.22 & & \\
\hline Perspective taking & 100 & 14 & $0.20^{\mathrm{ab} * * *}$ & 0.16 & 0.23 & & \\
\hline Composite EC/PT & 20 & 16 & $0.24^{\mathrm{b} * * *}$ & 0.18 & 0.29 & & \\
\hline \multicolumn{8}{|l|}{ Type of relationship } \\
\hline Type of parent-child relationship & 327 & 57 & & & & $F(2,324)=5.89$ & 0.003 \\
\hline No distinction (parents) & 69 & 29 & $0.21^{\mathrm{a} * * *}$ & 0.17 & 0.25 & & \\
\hline Mother & 136 & 28 & $0.17^{\mathrm{a} * * *}$ & 0.13 & 0.20 & & \\
\hline Father & 122 & 24 & $0.14^{\mathrm{b} * * *}$ & 0.10 & 0.17 & & \\
\hline \multicolumn{8}{|l|}{ Sample and study characteristics } \\
\hline Age & 302 & 54 & & & & $F(1,300)=0.00$ & 0.997 \\
\hline Intercept (centered) & & & $0.18 * * *$ & 0.16 & 0.21 & & \\
\hline Slope age & & & 0.00 & -0.01 & 0.01 & & \\
\hline$\%$ Girls & 314 & 51 & & & & $F(1,312)=0.35$ & 0.553 \\
\hline Intercept & & & $0.19 * * *$ & 0.14 & 0.24 & & \\
\hline Slope & & & 0.00 & -0.00 & 0.00 & & \\
\hline Ethnic composition & 277 & 34 & & & & $F(1,275)=0.41$ & 0.523 \\
\hline Majority & 253 & 29 & $0.15 * * *$ & 0.12 & 0.19 & & \\
\hline Mixed & 24 & 6 & $0.18 * * *$ & 0.11 & 0.25 & & \\
\hline Publication year (centered) & 327 & 57 & & & & $F(1,325)=2.81$ & 0.095 \\
\hline Intercept & & & $0.18 * * *$ & 0.15 & 0.21 & & \\
\hline Slope & & & 0.02 & 0.00 & 0.05 & & \\
\hline \multicolumn{8}{|l|}{ Measurement characteristics } \\
\hline Reliability RQ (centered) & 219 & 47 & & & & $\begin{array}{l}F(1,217)= \\
34.63\end{array}$ & $<0.001$ \\
\hline Intercept & & & $0.18 * * *$ & 0.15 & 0.21 & & \\
\hline Slope & & & $0.05 * * *$ & 0.03 & 0.06 & & \\
\hline Reliability empathy (centered) & 290 & 52 & & & & $F(1,288)=0.69$ & 0.409 \\
\hline Intercept & & & $0.18 * * *$ & 0.16 & 0.21 & & \\
\hline
\end{tabular}


Table 2 (continued)

\begin{tabular}{|c|c|c|c|c|c|c|c|}
\hline \multirow[t]{2}{*}{ Variable } & \multirow[t]{2}{*}{$k$} & \multirow[t]{2}{*}{$n_{\mathrm{sa}}$} & \multirow[t]{2}{*}{$r /$ slope } & \multicolumn{2}{|c|}{$95 \% \mathrm{CI}$} & \multirow[t]{2}{*}{$Q_{\mathrm{M}}$} & \multirow[t]{2}{*}{$p$-value } \\
\hline & & & & Lower & Upper & & \\
\hline Slope & & & -0.01 & -0.03 & 0.01 & & \\
\hline Informant RQ & 322 & 55 & & & & $F(1,320)=0.58$ & 0.448 \\
\hline Self & 286 & 54 & $0.18 * * *$ & 0.15 & 0.20 & & \\
\hline Parent & 36 & 5 & $0.19 * * *$ & 0.15 & 0.24 & & \\
\hline Informant empathy & 319 & 57 & & & & $F(1,317)=9.39$ & 0.002 \\
\hline Self & 297 & 54 & $0.18^{\mathrm{a} * * *}$ & 0.16 & 0.21 & & \\
\hline Observant & 22 & 6 & $0.06^{\mathrm{b}}$ & -.01 & 0.14 & & \\
\hline Assessment empathy & 327 & 57 & & & & $F(2,324)=4.07$ & 0.018 \\
\hline Questionnaire & 298 & 51 & $0.19^{\mathrm{a} * * *}$ & 0.17 & 0.22 & & \\
\hline Observation & 14 & 4 & $0.07^{\mathrm{b} *}$ & -0.03 & 0.16 & & \\
\hline Task & 15 & 4 & $0.11^{\mathrm{ab} *}$ & 0.02 & 0.20 & & \\
\hline Questionnaire empathy & 292 & 48 & & & & $F(3,288)=1.45$ & 0.229 \\
\hline IRI & 244 & 31 & $0.20^{\mathrm{a} * * *}$ & 0.17 & 0.23 & & \\
\hline IECA & 23 & 7 & $0.18^{\mathrm{ab} * * *}$ & 0.12 & 0.24 & & \\
\hline BES & 5 & 4 & $0.20^{\mathrm{ab} * * *}$ & 0.09 & 0.30 & & \\
\hline Emotional empathy scale & 20 & 6 & $0.11^{\mathrm{b} *}$ & 0.02 & 0.18 & & \\
\hline
\end{tabular}

Estimates with different subscripts differed significantly in strength

$k$ number of correlations, $n_{s a}$ number of samples, $R Q$ relationship quality, Composite EC/PT combination empathic concern and perspective taking, IRI Interpersonal Reactivity Index, IECA Index of Empathy for Children and Adolescents, BES Basic Empathy Scale

$* p<0.05, * * p<0.01, * * * p<0.001$

analysis showed that a stronger correlation between peer relationship quality and empathy was found in majority samples compared to mixed samples ${ }^{5}$. However, correlations of minority samples did not differ from correlations of majority or mixed samples. Furthermore, publication year did not significantly moderate the correlations (parentchild: $F(1,325)=2.81, p=0.095$; peer: $F(1,61)=0.00$, $p=0.995)$. Reliability of the relationship quality measurement moderated both correlations with parent-child $(F(1,217)=34.63, p<0.001)$ and peer relationship quality $(F(1,44)=20.39, p<0.001)$, such that stronger correlations were found with empathy when reliability of relationship quality was higher. Reliability of empathy measurement only moderated the correlation with peer relationship $(F(1,38)=7.68, p=0.009)$ and not with parent-child relationship quality $(F(1,288)=0.69, p=0.409)$. A stronger correlation between peer relationship quality and empathy was found when reliability of the empathy measurement was higher. The moderating roles of informant of relationship quality and empathy and assessment method of empathy could only be tested for the correlation with parent-child relationship quality, because of a lack of variety in

\footnotetext{
5 After controlling for reliability of empathy measures, correlations did not differ anymore for majority, minority, and mixed samples.
}

the peer relationship studies (mainly based on self-reported questionnaires). The results demonstrated that informant of parent-child relationship quality (self- vs. parent-reported) was not a significant moderator $(F(1,320)=0.58, p=$ $0.448)$, but informant (self- vs. observant-reported) $(F(1$, $317)=9.39, p=0.002$ ) and assessment method of empathy (questionnaire vs. observation vs. task) $(F(2,324)=4.07$, $p=0.018$ ) were significant moderators. Correlations were stronger when empathy was self-reported instead of observer-reported. Similarly, a stronger correlation was found when empathy was measured with a questionnaire compared to an observation. The correlation based on an empathy task (e.g., Reading the Mind in the Eyes Task) did not differ from the correlation based on a questionnaire measurement of empathy. Additionally, empathy questionnaire was not a significant moderator in the correlation between parent-child relationship quality and empathy $(F(3,288)=1.45, p=0.229)$. Nonetheless, contrast analysis showed a stronger correlation when the Interpersonal Reactivity Index was used compared to the Mehrabian and Epstein's Emotional Empathy Scale. The correlation based on the Emotional Empathy Scale did not differ from the correlations based on the Empathy Index for Children and Adolescents or the Basic Empathy Scale. 
Table 3 Results of the Association between Peer Relationship Quality and Empathy

\begin{tabular}{|c|c|c|c|c|c|c|c|}
\hline \multirow[t]{2}{*}{ Variable } & \multirow[t]{2}{*}{$k$} & \multirow[t]{2}{*}{$n_{\mathrm{sa}}$} & \multirow[t]{2}{*}{$r /$ slope } & \multicolumn{2}{|l|}{$95 \% \mathrm{CI}$} & \multirow[t]{2}{*}{$Q_{\mathrm{M}}$} & \multirow[t]{2}{*}{$p$-value } \\
\hline & & & & Lower & Upper & & \\
\hline Overall correlation & 63 & 31 & $0.29^{* * *}$ & 0.24 & 0.33 & & \\
\hline \multicolumn{8}{|l|}{ Moderator analyses } \\
\hline \multicolumn{8}{|l|}{ Dimensions } \\
\hline Dimension RQ & 63 & 31 & & & & $F(1,61)=13.90$ & $<0.001$ \\
\hline Positive & 49 & 30 & $0.30^{\mathrm{a}} * * *$ & 0.26 & 0.35 & & \\
\hline Negative (reverse coded) & 14 & 3 & $0.15^{\mathrm{b} * *}$ & 0.05 & 0.24 & & \\
\hline Positive indicator RQ & 21 & 18 & & & & $F(2,18)=0.31$ & 0.738 \\
\hline Warmth & 6 & 5 & $0.39^{* * *}$ & 0.28 & 0.49 & & \\
\hline Attachment & 9 & 9 & $0.35^{* * *}$ & 0.26 & 0.43 & & \\
\hline Friendship quality & 6 & 4 & $0.40^{* * *}$ & 0.26 & 0.52 & & \\
\hline Dimension empathy & 63 & 31 & & & & $F(2,60)=6.32$ & 0.003 \\
\hline Affective & 23 & 12 & $0.23^{\mathrm{a} * * *}$ & 0.16 & 0.28 & & \\
\hline Cognitive & 27 & 14 & $0.24^{\mathrm{a} * * *}$ & 0.18 & 0.30 & & \\
\hline Composite & 13 & 13 & $0.38^{\mathrm{b} * * *}$ & 0.31 & 0.44 & & \\
\hline Indicator empathy & 45 & 22 & & & & $F(2,42)=5.88$ & 0.006 \\
\hline Empathic concern & 19 & 9 & $0.22^{\mathrm{a} * * *}$ & 0.15 & 0.28 & & \\
\hline Perspective taking & 14 & 7 & $0.26^{\mathrm{a} * * *}$ & 0.18 & 0.34 & & \\
\hline Composite EC/PT & 12 & 12 & $0.38^{\mathrm{b} * * *}$ & 0.31 & 0.44 & & \\
\hline \multicolumn{8}{|l|}{ Type of relationship } \\
\hline Type peer relationship & 63 & 31 & & & & $F(2,60)=2.38$ & 0.101 \\
\hline Peer & 3 & 3 & $0.36^{* * *}$ & 0.21 & 0.49 & & \\
\hline Friend & 49 & 23 & $0.30^{* * *}$ & 0.25 & 0.35 & & \\
\hline Partner & 11 & 6 & $0.20^{* * *}$ & 0.10 & 0.30 & & \\
\hline \multicolumn{8}{|l|}{ Sample characteristics } \\
\hline Age & 61 & 30 & & & & $F(1,59)=3.91$ & 0.053 \\
\hline Intercept (centered) & & & $0.31^{* * *}$ & 0.26 & 0.36 & & \\
\hline Slope age & & & -0.02 & -0.05 & 0.00 & & \\
\hline$\%$ girls & 63 & 31 & & & & $F(1,61)=0.01$ & 0.907 \\
\hline Intercept & & & $0.28^{* * *}$ & 0.19 & 0.37 & & \\
\hline Slope & & & 0.00 & -0.00 & 0.00 & & \\
\hline Ethnicity & 44 & 19 & & & & $F(2,41)=5.13$ & 0.010 \\
\hline Majority & 33 & 10 & $0.40^{\mathrm{a} * * *}$ & 0.31 & 0.49 & & \\
\hline Minority & 4 & 3 & $0.30^{\mathrm{ab} * * *}$ & 0.15 & 0.43 & & \\
\hline Mixed & 7 & 6 & $0.22^{\mathrm{b} * * *}$ & 0.15 & 0.28 & & \\
\hline Publication year & 51 & 20 & & & & $F(1,61)=0.00$ & 0.995 \\
\hline Intercept (centered) & & & $0.29^{* * *}$ & 0.24 & 0.34 & & \\
\hline Slope & & & 0.00 & -0.05 & 0.05 & & \\
\hline \multicolumn{8}{|c|}{ Measurement characteristics } \\
\hline Reliability RQ & 46 & 26 & & & & $F(1,44)=20.39$ & $<0.001$ \\
\hline Intercept (centered) & & & $0.30^{* * * *}$ & 0.25 & 0.35 & & \\
\hline Slope & & & $0.09^{* * *}$ & 0.05 & 0.14 & & \\
\hline Reliability empathy & 40 & 25 & & & & $F(1,38)=7.68$ & 0.009 \\
\hline Intercept (centered) & & & $0.28^{* * *}$ & 0.23 & 0.33 & & \\
\hline Slope & & & $0.07 * *$ & 0.02 & 0.12 & & \\
\hline
\end{tabular}

Estimates with different subscripts differed significantly in strength

$k$ number of correlations, $n_{s a}$ number of samples, $R Q$ relationship quality, Composite EC/PT combination empathic concern and perspective taking $* p<0.05, * * p<0.01, * * * p<0.001$

\section{Sensitivity Analysis}

The positive and negative dimensions of relationship quality can be considered as distinct constructs, such that lower levels of negativity might not by definition represent higher relationship quality. Therefore, sensitivity analyses were conducted to check whether results of the previous described moderator analyses were different when data of the positive and negative relationship quality dimensions were separately analyzed and the effect sizes of the negative dimension were not reverse coded (thus original effect size, with negative correlations representing higher levels of 
Table 4 Tests for Publication Bias

\begin{tabular}{|c|c|c|c|c|}
\hline & \multicolumn{4}{|c|}{ Parent-child relationship quality and empathy } \\
\hline & \multicolumn{3}{|c|}{ Funnel plot symmetry } & \multirow[t]{2}{*}{ Fail-safe $N$} \\
\hline & $z$-value & $p$-value & & \\
\hline Relationship quality & 0.92 & 0.356 & & 16729 \\
\hline Positive & 0.93 & 0.354 & & 15986 \\
\hline Negative & 1.91 & 0.055 & & 247 \\
\hline Empathy & 0.92 & 0.356 & & 16729 \\
\hline Affective & 2.44 & 0.015 & & 4365 \\
\hline Cognitive & -0.52 & 0.603 & & 2167 \\
\hline \multirow[t]{4}{*}{ Composite } & 0.19 & 0.851 & & 3398 \\
\hline & \multicolumn{4}{|c|}{ Peer relationship quality and empathy } \\
\hline & \multicolumn{3}{|c|}{ Funnel plot symmetry } & \multirow[t]{2}{*}{ Fail-safe $N$} \\
\hline & $z$-value & $p$-value & & \\
\hline Relationship quality & -2.62 & 0.009 & 23453 & \\
\hline Positive & -1.86 & 0.062 & 23685 & \\
\hline Negative & 0.54 & 0.586 & 11 & \\
\hline Empathy & -2.62 & 0.009 & 23453 & \\
\hline Affective & 0.12 & 0.904 & 1026 & \\
\hline Cognitive & -1.47 & 0.141 & 2265 & \\
\hline Composite & -0.62 & 0.536 & 9750 & \\
\hline
\end{tabular}

negativity and lower levels of empathy). For peer relationship quality, moderator analysis on the separate dimensions could only be performed with the positive dimension, as not enough studies were present for the negative dimension (three studies) to run moderator analyses. Results of the sensitivity analyses are displayed in Online Resources 1, 2, and 3.

With respect to hypothesized moderators, two differences were found when comparing results of the moderator analyses performed on the complete correlational data or on the data of the separate relationship quality dimensions. First, when examining empathy indicator as a moderator in the association between the positive dimension of parentchild relationship quality and empathy, the correlations with empathic concern and perspective taking became different in strength. Such that the correlation with perspective taking was stronger than the correlation with empathic concern. Second, when examining type of parent-child relationship as a moderator in the association between the negative dimension of parent-child relationship quality and empathy, the correlations for mothers and father were not different in strength anymore.

\section{Testing Publication Bias}

The results of the Egger's regression test demonstrated funnel plot asymmetry for (1) the correlation between parent-child relationship quality and affective empathy, (2) the overall correlation between peer relationship quality and empathy, and (3) the correlation between the positive dimension of peer relationship quality and empathy (see Table 4). After using the trim and fill method, a slightly weaker correlation was found between parent-child relationship quality and affective empathy $(r=0.17, p<0.001$, $95 \%$ CI $[0.14,0.20]$, and stronger correlations were found for the overall correlation peer relationship quality and empathy ( $r=0.35, p<0.001,95 \%$ CI [0.30, 0.39]) and between the positive dimension of peer relationship quality and empathy $(r=0.36, p<0.001,95 \%$ CI $[0.31,0.40])$. Furthermore, according to Rosenthal's criterion $(n \times 5+10)$ (Rosenthal 1995), results of the Fail-safe method indicated that the correlation between the negative dimension of peer relationship quality and empathy is likely an artifact of publication bias (see Table 4).

\section{Discussion}

Empathy, or the ability to feel concern for and to understand others' feelings, is thought to develop in high quality relationships with parent and peers, but also to facilitate the quality of these relationships. Studies on adolescent relationship quality and empathy have assessed a variety of relationship quality indicators (e.g., support, conflict, 
satisfaction) and have made a distinction between affective and cognitive empathy. Therefore, uncertainty remained about how parent-child and peer relationship quality were associated with empathy in adolescence. In order to enhance the understanding of how these constructs are associated, the present meta-analysis was conducted. The meta-analysis applied a multilevel approach in order to include multiple effect sizes from one study or sample, thus allowing to extract all available empirical data. In total, 390 effect sizes from 70 studies, assessing 75 independent samples, were retrieved. In line with hypotheses, the results indicated that both parent-child and peer relationship quality were positively associated with adolescent empathy. However, as expected, empathy was more strongly associated with peer relationship quality than with parent-child relationship quality. Moreover, although many moderators did not appear to affect the strength of the associations (e.g., age and gender), several significant moderators were identified, such as relationship quality dimension (positive vs. negative dimension) and gender of the parent (mother vs. father). Hence, the present meta-analysis demonstrates that adolescents with higher quality relationships, particularly with peers, have indeed more concern for and a better understand of others' emotions.

\section{Parent-Child versus Peer Relationship Quality}

The results of the meta-analysis confirmed that adolescents with higher quality parent-child and peer relationships have higher levels of empathy compared to adolescents with lower quality relationships. This is in line with socialization theories describing the facilitating role of supportive relationships in the development of empathy, for example by modelling (Barnett 1987), and the expectation that empathy promotes relationship quality through more constructive conflict behavior (e.g. Van Lissa et al. 2016). Furthermore, a stronger correlation of empathy with peer relationship quality than with parent-child relationship quality was found. This is in accordance with socialization theories positing a more influential role of peers compared to parents in adolescence (Youniss and Smoller 1985). Additionally, as adolescence is a period in which time spent with peers increases and peer relationships become more intimate (Furman and Buhrmester 1992; Larson and Richards 1991), empathy may be more important to gain and maintain high quality peer relationships than to maintain high quality parent-child relationships. However, since the metaanalytic results are based on correlational studies investigating relative inter-individual differences in adolescents' empathy and relationship quality, it cannot be certain that these positive correlations also reflect over-time processes of facilitative effects of relationship quality on empathy or vice versa (Hamaker 2012). Nonetheless, this meta-analysis including 70 studies powerfully indicates that relative interindividual differences in empathy and relationship quality, particularly regarding relationships with peers, are related in adolescence, and encourages future studies to investigate the underlying intra-individual processes (e.g., Lam et al. 2012) that may form these inter-individual differences.

\section{Explaining Heterogeneity with Moderators}

\section{Dimensions of relationship quality and empathy}

As expected, the results showed that the positive dimensions of parent-child and peer relationship quality were positively related to empathy and the negative dimensions were negatively related to empathy in adolescence. Additionally, the correlations with the positive dimensions were stronger than with the negative dimensions. The finding that the positive dimension of relationship quality is stronger related to empathy than the negative dimension, can be explained by the conceptual connection between empathy and the positive dimension of relationship quality. That is, warmth and support in relationships with parents or peers imply concern and understanding for adolescents' emotions and this provides the adolescent with a model of empathy. Nonetheless, it should be noted that only fourteen effect sizes from three studies could be included of the negative dimension of peer relationship quality, and hence future analyses involving more correlations can provide a more reliable conclusion regarding the association between negative peer relationship quality and empathy in adolescence.

Moreover, the dimensions affective and cognitive empathy were not differently related to parent-child and peer relationship quality in adolescence. However, when examining the positive and negative dimension of parentchild relationship quality separately, the positive dimension of parent-child relationship quality was more strongly related to perspective taking than to empathic concern. Nonetheless, the positive dimension of parent-child relationship quality was not differently related to a combination score of perspective taking and empathic concern compared to the separate scores of perspective taking or empathic concern. Hence, the meta-analytic findings were contrary to the hypotheses that affective empathy would most strongly be associated with parent-child relationship quality and cognitive empathy with peer relationship quality, which were based on socialization theories emphasizing different aspects of empathy. The findings suggest that adolescents who both show more concern for and a better understanding of others' emotions experience higher quality relationships with parents and peers. 
Additionally, a composite score of affective and cognitive responses was most strongly associated with parentchild and peer relationship quality compared to separate scores of affective and/or cognitive responses. One possible explanation is that empathy is more reliably measured when taking into account both affective and cognitive responses, for example, simply because the measure consists of more items. Another explanation is that being high on either cognitive empathy or affective empathy is not enough, but that it takes both to maintain higher quality relationships. Although affective and cognitive empathy were similarly related to relationship quality, they tap into different aspects of empathy that are both beneficial for relational functioning. This is in line with previous studies showing that perspective taking alone did not predict adolescents' prosocial behavior, but that it predicted prosocial behavior either indirectly through its association with affective empathy (Van der Graaff et al. 2018) or in interaction with affective empathy (e.g., Eisenberg et al. 2001). Nonetheless, assessing the dimensions separately, but preferably simultaneously, is still of interest as this gives insight in how affective and cognitive empathy, and their combination, facilitate high quality relationships.

\section{Type of parent-child and peer relationship}

In line with the hypothesis, the moderation analyses showed that mother-child relationship quality was more strongly associated with empathy in adolescence than father-child relationship quality. As adolescent generally spend more time with their mothers than with their fathers (Yeung et al. 2001) and fathers are less aware of their children's prosocial behavior (Hastings et al. 2007), the positive loop between constructive interpersonal behaviors within the relationship and adolescent empathy might be stronger in motheradolescent dyads. This is also supported by the results of the sensitivity analyses suggesting that this is particularly true for the positive dimension of parent-child relationship quality and not for the negative dimension. Regarding relationship quality with friends versus romantic partners, correlations with empathy did not differ. However, it should be noted that only six samples from three studies assessing romantic relationship quality were included, whereas there were twenty-three samples from twenty studies assessing friendship quality. Furthermore, a comparison with sibling relationship quality could not be made as only two studies were available. Therefore, more studies on the associations of romantic relationship quality and sibling relationship quality with adolescent empathy are needed in order to draw a more robust conclusion about the (dis)similarity of the correlations of empathy with different types of peer relationships.
Age, gender, and additional sample, study, and measurement characteristics

It was expected that the associations of parent-child and peer relationship quality with empathy would differ in strength across adolescence and between boys and girls because of differences in socialization processes (e.g., Bem 1981) and changes within relationships across adolescence (Smetana et al. 2006). However, associations varied neither with age nor gender, and the strength of both associations of parent-child and peer relationship quality with empathy appeared rather robust in adolescence. Furthermore, some additional moderators were tested. Results indicated that the strength of the correlation between parent-child relationship quality and empathy was higher (I) when reliability of the parent-child relationship quality measurement was higher and (II) when empathy was measured with self-reported questionnaires compared to observational data. Concerning the association between peer relationship quality and empathy, analyses showed that the strength of this correlation was higher when (I) measured in mixed ethnic samples compared to majority samples and (II) reliability of peer relationship quality and empathy was higher. However, the correlations of the mixed samples were based on more reliable empathy data (average reliability of 0.81 ) compared to the correlations of the majority samples (average reliability of 0.72 ). After controlling for the reliability of the empathy measurements, correlations between peer relationship quality and empathy did not differ any longer for mixed and majority samples. Furthermore, the moderating effect of informant of the reports of relationship quality and empathy, and assessment method of relationship quality could not be tested in this association due to a lack of data. Thus, less reliable measures of both relationship quality and empathy appeared to be a factor that explained findings of less strong associations, but not enough variation in assessment method was present to assess this as a moderator for explaining heterogeneity in the association between peer relationship quality and empathy in adolescence.

\section{Strengths, Limitations, and Directions for Future Research}

The present meta-analysis is the first to examine the associations between parent-child and peer relationship quality and empathy in adolescence. A multilevel meta-analysis approach (Van den Noortgate et al. 2015) enables to include multiple effect sizes within studies, allowing to incorporate all relevant data that was available. Moreover, a search in several relevant electronic databases was conducted by using a broad range of related key words. The comprehensive nature of the database search was confirmed by the fact that only found two additional studies were found 
through backwards citation search. Furthermore, a considerable number of moderators enabled to answer longstanding questions, such as differences between affective and cognitive empathy, and genders. However, the associations of empathy with parent-child and peer relationship quality appeared robust and significant across different types of relationships, dimensions of empathy, age and gender, suggesting that empathy and relationship are consistently related in adolescence.

Notwithstanding these strengths, some limitations should be considered. First, only 26 of the 70 included studies examined the association between peer relationship quality and empathy. Of these studies, only 14 effect sizes were retrieved that examined the association between the negative dimension of peer relationship quality and adolescent empathy. As a consequence, the estimation of the true effect size linking peer relationship quality and empathy is less precise than the estimation for the association between the negative dimension of parent-child relationship quality and empathy. Moreover, it was impossible to include sibling relationship quality due to a lack of eligible studies. Hence, it is recommended that future studies focus on the role of peer relationship quality, and in particular relationships with siblings, in adolescent empathy. Second, the investigated associations were concurrent, and therefore, findings of the present study cannot be translated to longitudinal effects. To the best of our knowledge, the literature predominantly consists of cross-sectional studies, and hence, it is recommended that future studies consider longitudinal associations between empathy and relationship quality. Third, no conclusions can be drawn with respect to intra-individual processes that occur over time, as correlations were examined that demonstrate cross-sectional relative differences between adolescents in relationship quality and empathy. Conducting longitudinal within-person studies is an important next step to assess the reciprocal intra-individual processes between relationship quality and empathy in adolescence.

\section{Conclusion}

The present meta-analysis investigated the associations between parent-child and peer relationship quality and empathy in adolescents. Because empirical studies on this topic varied greatly in design, ambiguity remained about how relationship quality with parents and peers is associated with adolescent empathy. In order to provide a better comprehension of these associations, the present metaanalysis applied a multilevel approach to synthesize all available data. As expected, the results demonstrated that adolescents with higher quality parent-child and peer relationships show more concern for and a better understanding of others' emotions than adolescents with poorer parent- child and peer relationships. These associations appeared rather robust. Additionally, the moderator analyses indicated some significant moderators that explained differences in strength, such as relationship quality dimension and type of parent-child relationship. To conclude, the findings imply that good empathic abilities may be protective for experiencing poor relationships and that higher quality relationships might facilitate the development of empathic skills. As poor interpersonal functioning is related to maladaptation, such as heightened levels of depressive feelings (e.g., Zhang et al. 2018), the present study contributes to an improved comprehension of protective factors of poor interpersonal functioning during adolescence.

Authors' Contributions S.B. (first author) conceived of the study, conducted the systematic search, coded and analyzed the data, and drafted and revised the article; J.v.d.G. conceived of the study, conducted the systematic search and coded the data, and helped revise the article; M.d.W. and S.B. (last author) contributed to the revision; I.E.v. d.V. contributed to the data analyses and revision; E.C. contributed to the interpretation of the results and revision. All authors read and approved the final manuscript.

Data Sharing and Declaration Data and syntaxes are made openly available and can be found on https://osf.io/frkct/.

\section{Compliance with Ethical Standards}

Conflict of Interest The authors declare that they have no conflict of interest.

Publisher's note: Springer Nature remains neutral with regard to jurisdictional claims in published maps and institutional affiliations.

Open Access This article is distributed under the terms of the Creative Commons Attribution 4.0 International License (http://crea tivecommons.org/licenses/by/4.0/), which permits use, duplication, adaptation, distribution, and reproduction in any medium or format, as long as you give appropriate credit to the original author(s) and the source, provide a link to the Creative Commons license, and indicate if changes were made.

\section{References}

*Included in the meta-analysis.

*Adams, G. R., Jones, R. M., Schvaneveldt, J. D., \& Jenson, G. O. (1982). Antecedents of affective role-taking behaviour: Adolescent perceptions of parental socialization styles. Journal of Adolescence, 5, 259-265. https://doi.org/10.1016/S0140-1971(82)80029-8.

*Antonopoulou, K., Alexopoulos, D. A., \& Maridaki-Kassotaki, K. (2012). Perceptions of father parenting style, empathy, and selfesteem among Greek preadolescents. Marriage and Family Review, 48, 293-309. https://doi.org/10.1080/01494929.2012.665016.

Assink, M., \& Wibbelink, C. J. M. (2016). Fitting three-level metaanalytic models in R: A step-by-step tutorial. The Quantitative Methods for Psychology, 12, 154-174. https://doi.org/10.20982/ tqmp.12.3.p154.

Barnett, M. A. (1987). Empathy and related responses in children. In N. Eisenberg \& J. Strayer Eds., Empathy and its development. New York, NY: Cambridge University Press. 
Batanova, M. D., \& Loukas, A. (2011). Social anxiety and aggression in early adolescents: Examining the moderating roles of empathic concern and perspective taking. Journal of Youth and Adolescence, 40, 1534-1543. https://doi.org/10.1007/s10964-011-9634-x.

*Batanova, M. D., \& Loukas, A. (2012). What are the unique and interacting contributions of school and family factors to early adolescents' empathic concern and perspective taking? Journal of Youth and Adolescence, 41, 1382-1391. https://doi.org/10.1007/ s10964-012-9768-5.

*Batanova, M., \& Loukas, A. (2014). Unique and interactive effects of empathy, family, and school factors on early adolescents' aggression. Journal of Youth and Adolescence, 43, 1890-1902. https://doi.org/10.1007/s10964-013-0051-1.

Bem, S. L. (1981). Gender schema theory: A cognitive account of sex typing. Psychological Review, 88, 354-364. https://doi.org/10. 1037/0033-295X.88.4.354.

*Black, A. E., \& Pedro-Carrol, J. (1993). Role of parent-child relationships in mediating the effects of marital disruption. Journal of the American Academy of Child and Adolescent Psychiatry, 32, 1019-1027. https://doi.org/10.1097/00004583-19930900000021.

Borenstein, M., Hedges, L. V., Higgins, J. P. T., \& Rothstein, H. R. (2011). Introduction to Meta-Analysis.. Chichester, England: John Wiley and Sons. https://doi.org/10.1002/9780470743386. fmatter.

Bowlby, J. (1982). Attachment and loss: Volume I attachment. New York, NY: Basic Books. (second).

Buhrmester, D., \& Furman, W. (1987). The development of companionship and intimacy. Child Development, 58, 1101-1113. https://doi.org/10.1111/j.1467-8624.1987.tb01444.x.

*Carlo, G., McGinley, M., Hayes, R., Batenhorst, C., \& Wilkinson, J. (2007). Parenting styles or practices? Parenting, sympathy, and prosocial behaviors among adolescents. The Journal of Genetic Psychology, 168, 147-176. https://doi.org/10.3200/GNTP.168.2. 147-176.

Carlo, G., Mestre, M. V., Samper, P., Tur, A., \& Armenta, B. E. (2011). The longitudinal relations among dimensions of parenting styles, sympathy, prosocial moral reasoning, and prosocial behaviors. International Journal of Behavioral Development, 35 , 116-124. https://doi.org/10.1177/0165025410375921.

*Carlo, G., Raffaelli, M., Laible, D. J., \& Meyer, K. A. (1999). Why are girls less physically aggressive than boys? Personality and parenting mediators of physical aggression. Sex Roles, 40(9-10), 711-729.

*Carlo, G., Roesch, S. C., \& Melby, J. (1998). The multiplicative relations of parenting and temperament to prosocial and antisocial behaviors in adolescence. The Journal of Early Adolescence, 18, 266-290. https://doi.org/10.1177/0272431698018003003.

Carlo, G., Streit, C., \& Crockett, L. (2018). Generalizability of a traditional social cognitive model of prosocial behaviors to US Latino/a youth. Cultural Diversity and Ethnic Minority Psychology, 24, 596-604. https://doi.org/10.1037/cdp0000188.

Cheung, M. W.-L. (2014). Modeling dependent effect sizes with threelevel meta-analyses: a structural equation modeling approach. Psychological Methods, 19, 211-229. https://doi.org/10.1037/a 0032968.

*Chow, C. M., Ruhl, H., \& Buhrmester, D. (2013). The mediating role of interpersonal competence between adolescents' empathy and friendship quality: A dyadic approach. Journal of Adolescence, 36, 191-200. https://doi.org/10.1016/j.adolescence.2012.10.004.

*Christensen, K. J., Padilla-Walker, L. M., Busby, D. M., Hardy, S. A., \& Day, R. D. (2011). Relational and social-cognitive correlates of early adolescents' forgiveness of parents. Journal of Adolescence, 34, 903-913. https://doi.org/10.1016/j.adolescence.2011.01.001.

Cohen, J. (1992). A power primer. Psychological Bulletin, 112, 155159. https://doi.org/10.1037/0033-2909.112.1.155.
Crocetti, E. (2016). Systematic reviews with meta-analysis: Why, when, and how?. Emerging Adulthood, 4, 3-18. https://doi.org/ $10.1177 / 2167696815617076$.

Courtain, A., \& Glowacz, F. (2018). Youth's conflict resolution strategies in their dating relationships. Journal of Youth and Adolescence, 1-13. https://doi.org/10.1007/s10964-018-0930-6.

*Curcio, A. L., Mak, A. S., \& George, A. M. (2017). Predictors of delinquency among adolescents and young adults: A new psychosocial control perspective. Australian and New Zealand Journal of Criminology, 50, 155-175. https://doi.org/10.1177/ 0004865816628594.

"Daniel, E., Dys, S. P., Buchmann, M., \& Malti, T. (2016). Developmental trajectories of social justice values in adolescence: Relations with sympathy and friendship quality. Social Development, 25, 548-564. https://doi.org/10.1111/sode.12146.

Davis, M. H. (1983). Measuring individual differences in empathy: Evidence for a multidimensional approach. Journal of Personality and Social Psychology, 44, 113-126. https://doi.org/10. 1037/0022-3514.44.1.113.

Decety, J., \& Jackson, P. L. (2004). The functional architecture of human empathy. Behavioral and Cognitive Neuroscience Reviews, 3, 71-100. https://doi.org/10.1177/1534582304267187.

Decety, J., \& Michalska, K. J. (2012). How children develop empathy: the contribution of developmental affective neuroscience. In J. Decety (Ed.), Empathy: From Bench to Bedside (pp. 3-20). Cambridge, MA: MIT Press.

Del Re, A.C. (2013). compute.es: Compute Effect Sizes. R package version 0.2-2. URL http://cran.r-project.org/web/packages/ compute.es.

De Goede, I. H., Branje, S. J., \& Meeus, W. H. (2009a). Developmental changes in adolescents' perceptions of relationships with their parents. Journal of Youth and Adolescence, 38, 75-88. https://doi.org/10.1007/s10964-008-9286-7.

De Goede, I. H., Branje, S. J., \& Meeus, W. H. (2009b). Developmental changes and gender differences in adolescents' perceptions of friendships. Journal of Adolescence, 32, 1105-1123. https://doi.org/10.1016/j.adolescence.2009.03.002.

"De Kemp, R. A. T., Overbeek, G., de Wied, M., Engels, R. C. M. E., \& Scholte, R. H. J. (2007). Early adolescent empathy, parental support, and antisocial behavior. Journal of Genetic Psychology, 168, 5-18. https://doi.org/10.3200/GNTP.168.1.5-18.

"De Los Reyes, A., Lerner, M. D., Thomas, S. A., Daruwala, S., \& Goepel, K. (2013). Discrepancies between parent and adolescent beliefs about daily life topics and performance on an emotion recognition task. Journal of Abnormal Child Psychology, 41, 971-982. https://doi.org/10.1007/s10802-013-9733-0.

De Wied, M., Branje, S. J. T., \& Meeus, W. H. J. (2007). Empathy and conflict resolution in friendship relations among adolescents. Aggressive Behavior, 33, 48-55. https://doi.org/10.1002/ab. 20166.

Duval, S., \& Tweedie, R. (2000). Trim and fill: A simple funnel-plotbased method. Biometrics, 56, 455-463. https://doi.org/10.1111/j. 0006-341x.2000.00455.x.

Egger, M., Smith, G. D., Schneider, M., \& Minder, C. (1997). Bias in meta-analysis detected by a simple, graphical test. British Medical Journal, 315, 629-634. https://doi.org/10.1136/bmj.315. 7109.629.

Eisenberg, N., Eggum, N. D., \& Di Giunta, L. (2010). Empathyrelated responding: Associations with prosocial behavior, agression, and intergroup relations. Social Issues and Policy Review, 4, 143-180. https://doi.org/10.1111/j.1751-2409.2010.01020.x.

Eisenberg, N., \& Fabes, R. A. (1990). Empathy: Conceptualization, measurement, and relation to prosocial behavior. Motivation and Emotion, 14, 131-149. https://doi.org/10.1007/BF00991640.

Eisenberg, N., Spinrad, T. L., \& Morris, A. (2003). Empathy-related responding in children. In M. Killen \& J. G. Smetana (Eds.), 
Handbook of moral development (pp. 184-207). New York, NY: Psychology Press.

Eisenberg, N., Zhou, Q., \& Koller, S. (2001). Brazilian adolescents' prosocial moral judgment and behavior: Relations to sympathy, perspective taking, gender-role orientation, and demographic characteristics. Child Development, 72, 518-534. https://doi.org/ 10.1111/1467-8624.00294.

*Estévez López, E., Jiménez, T. I., \& Moreno, D. (2018). Aggressive behavior in adolescence as a predictor of personal, family, and school adjustment problems. Psicothema, 30(1), 66-73. https:// doi.org/10.7334/psicothema2016.294.

*Furlong, M. J., You, S., Shishim, M., \& Dowdy, E. (2017). Development and validation of the social emotional health surveyhigher education version. Applied Research in Quality of Life, 12, 343-367. https://doi.org/10.1007/s11482-016-9464-9.

Furman, W. (1998). The measurement of friendship perceptions: Conceptual and methodological issues. In W. M. Bukowski, A. F. Newcomb \& W. W. Hartup (Eds.), The company they keep: Friendship in childhood and adolescence (pp. 41-65). New York, NY: Cambridge University Press.

Furman, W., \& Buhrmester, D. (1992). Age and sex differences in perceptions of networks of personal relationships. Child Development, 63, 103-115. https://doi.org/10.1111/j.1467-8624.1992. tb03599.x.

*Green, L. M., Missotten, L., Tone, E. B., \& Luyckx, K. (2018). Empathy, depressive symptoms, and self-esteem in adolescence: The moderating role of the mother-adolescent relationship. Journal of Child and Family Studies, 27, 3964-3974. https://doi. org/10.1007/s10826-018-1216-z.

Hamaker, E. L. (2012). Why researchers should think "within-person": A paradigmatic rationale. In M. R. Mehl \& T. S. Conner (Eds.), Handbook of Research Methods for Studying Daily Life (pp. 4361). New York, NY: Guilford.

Harper, J. M., Padilla-Walker, L. M., \& Jensen, A. C. (2016). Do siblings matter independent of both parents and friends? Sympathy as a mediator between sibling relationship quality and adolescent outcomes. Journal of Research on Adolescence, 26, 101-114. https://doi.org/10.1111/jora.12174.

Hastings, P. D., Utendale, W. T., \& Sullivan, C. (2007). The socialization of prosocial development. In J. E. Grusec \& P. D. Hastings (Eds.), Handbook of socialization (pp. 638-664). New York: Guilford Press.

*Haugen, P. T., Welsh, D. P., \& McNulty, J. K. (2008). Empathic accuracy and adolescent romantic relationships. Journal of Adolescence, 31, 709-727. https://doi.org/10.1016/j.adolescence. 2008.03.003.

*Heller, S. R., Robinson, L. C., Henry, C. S., \& Plunkett, S. W. (2007). Gender differences in adolescent perceptions of parent-adolescent openness in communication and adolescent empathy. Marriage and Family Review, 40, 103-122. https://doi.org/10.1300/ J002v40n04_06.

*Henry, C. S., Nichols, J. P., Robinson, L. C., \& Neal, R. A. (2005). Parent and stepparent support and psychological control in remarried families and adolescent empathic concern. Journal of Divorce and Remarriage, 43, 29-46. https://doi.org/10.1300/ J087v43n03_02.

*Henry, C. S., Sager, D. W., \& Plunkett, S. W. (1996). Adolescents' perceptions of family system characteristics, parent-adolescent dyadic behaviors, adolescent qualities, and adolescent empathy. Family Relations, 45, 283-292. https://doi.org/10.2307/585500.

Hoffman, M. L. (2000). Empathy and prosocial behavior. In M. Lewis, J. M. Haviland-Jones, \& L. Felman Barret (Eds.), Handbook of emotions (Third, pp. 440-455). New York, NY: Guilford Press. https://doi.org/10.2307/2076468.

*Humfress, H., O'Connor, T. G., Slaughter, J., Target, M., \& Fonagy, P. (2002). General and relationship-specific models of social cognition: Explaining the overlap and discrepancies. Journal of Child Psychology and Psychiatry, 43, 873-883.

*Hünefeldt, T., Laghi, F., Ortu, F., \& Belardinelli, M. O. (2013). The relationship between 'theory of mind' and attachment-related anxiety and avoidance in Italian adolescents. Journal of Adolescence, 36, 613-621. https://doi.org/10.1016/j.adolescence.2013. 03.012 .

*Ingoglia, S., Lo Coco, A., Liga, F., \& Lo Cricchio, M. G. (2011). Emotional separation and detachment as two distinct dimensions of parent-adolescent relationships. International Journal of Behavioral Development, 35, 271-281. https://doi.org/10.1177/ 0165025410385878.

*Johnson, D. H., Wernli, M. A., \& LaVoie, J. C. (2013). Situational, interpersonal, and intrapersonal characteristic associations with adolescent conflict forgiveness. Journal of Genetic Psychology, 174, 291-315. https://doi.org/10.1080/00221325.2012.670672.

Jolliffe, D., \& Farrington, D. P. (2006). Development and validation of the Basic Empathy Scale. Journal of Adolescence, 29, 589-611. https://doi.org/10.1016/j.adolescence.2005.08.010.

Kennedy Root, A., \& Denham, S. A. (2010). The role of gender in the socialization of emotion: Key concepts and critical issues. In A. Kennedy Root \& S. A. Denham (Eds.), The role of gender in the socialization of emotion: Key concepts and critical issues. New directions for child and adolescent development (Vol. 128, pp. 19). San Francisco, CA: Jossey-Bass. https://doi.org/10.1002/cd. 265.

*Kenny, M. E., \& Gallagher, La (2002). Instrumental and social/ relational correlates of perceived maternal and paternal attachment in adolescence. Journal of Adolescence, 25, 203-219. https://doi.org/10.1006/jado.2002.0461.

*Laghi, F., D’Alessio, M., Pallini, S., \& Baiocco, R. (2009). Attachment representations and time perspective in adolescence. Social Indicators Research, 90, 181-194. https://doi.org/10.1007/ s11205-008-9249-0.

*Laible, D. (2007). Attachment with parents and peers in late adolescence: Links with emotional competence and social behavior. Personality and Individual Differences, 43, 1185-1197. https:// doi.org/10.1016/j.paid.2007.03.010.

*Laible, D. J., \& Carlo, G. (2004). The differential relations of maternal and paternal support and control to adolescent social competence, self-worth, and sympathy. Journal of Adolescent Research, 19, 759-782. https://doi.org/10.1177/0743558403260094.

"Laible, D. J., Carlo, G., \& Raffaelli, M. (2000). The differential relations of parent and peer attachment to adolescent adjustment. Journal of Youth and Adolescence, 29, 45-59. https://doi.org/10. 1023/A:1005169004882.

*Laible, D. J., Carlo, G., \& Roesch, S. C. (2004). Pathways to selfssteem in late adolescence: The role of parent and peer attachment, empathy, and social behaviours. Journal of Adolescence, 27, 703-716. https://doi.org/10.1016/j.adolescence.2004.05.005.

*Lam, C. B., Solmeyer, A. R., \& McHale, S. M. (2012). Sibling relationships and empathy across the transition to adolescence. Journal of Youth and Adolescence, 41, 1657-1670. https://doi. org/10.1007/s10964-012-9781-8.

Larson, R., \& Richards, M. H. (1991). Daily companionship in late childhood and early adolescence: Changing developmental contexts. Child Development, 62, 284-300. https://doi.org/10.2307/ 1131003.

Larson, R. W., Richards, M. H., Moneta, G., Holmbeck, G., \& Duckett, E. (1996). Changes in adolescents' daily interactions with their families from ages 10 to 18: Disengagement and transformation. Developmental Psychology, 32, 744-754. https:// doi.org/10.1037/0012-1649.32.4.744.

Laursen, B., \& Bukowski, W. M. (1997). A developmental guide to the organisation of close relationships. Journal of Behavioral Development, 21, 747-770. https://doi.org/10.1080/016502597384659.A. 
Laursen, B., DeLay, D., \& Adams, R. E. (2010). Trajectories of perceived support in mother-adolescent relationships: The poor (quality) get poorer. Developmental Psychology, 46, 1792-1798. https://doi.org/10.1037/a0020679.

*Lereya, S. T., Humphrey, N., Patalay, P., Wolpert, M., Böhnke, J. R., Macdougall, A., \& Deighton, J. (2016). The student resilience survey: Psychometric validation and associations with mental health. Child and Adolescent Psychiatry and Mental Health, 10, 10-44. https://doi.org/10.1186/s13034-016-0132-5.

"Li, X., Bian, C., Chen, Y., Huang, J., Ma, Y., Tang, L., \& Yu, Y. (2015). Indirect aggression and parental attachment in early adolescence: Examining the role of perspective taking and empathetic concern. Personality and Individual Differences, 86, 499-503. https://doi.org/10.1016/j.paid.2015.07.008.

*Llorca-Mestre, A., Samper-García, P., Malonda-Vidal, E., \& CortésTomás, M. T. (2017). Parenting style and peer attachment as predictors of emotional instability in children. Social Behavior and Personality, 45, 677-694. https://doi.org/10.2224/sbp.5363.

*Marshall, S., Adams, G. R., \& Ryan, B. A. (2001). Distributive-justice reasoning in families with adolescents. Journal of Family Issues, 22, 107-123. https://doi.org/10.1177/019251301022001005.

*McGinley, M. (2018). Can hovering hinder helping? Examining the joint effects of helicopter parenting and attachment on prosocial behaviors and empathy in emerging adults. The Journal of Genetic Psychology, 179, 102-115. https://doi.org/10.1080/ 00221325.2018.1438985.

*McLaren, R. M., \& Pederson, J. R. (2014). Relational communication and understanding in conversations about hurtful events between parents and adolescents. Journal of Communication, 64, 145166. https://doi.org/10.1111/jcom.12072.

*Meuwese, R., Cillessen, A. H. N., \& Güroğlu, B. (2017). Friends in high places: A dyadic perspective on peer status as predictor of friendship quality and the mediating role of empathy and prosocial behavior. Social Development, 26, 503-519. https://doi.org/ 10.1111/sode.12213.

*Miklikowska, M., Duriez, B., \& Soenens, B. (2011). Family roots of empathy-related characteristics: The role of perceived maternal and paternal need support in adolescence. Developmental Psychology, 47, 1342-1352. https://doi.org/10.1037/a0024726.

"Miklikowska, M., \& Hurme, H. (2011). Democracy begins at home: Democratic parenting and adolescents' support for democratic values. European Journal of Developmental Psychology, 8, 541557. https://doi.org/10.1080/17405629.2011.576856.

Morris, A. S., Silk, J. S., Steinberg, L., Myers, S. S., \& Robinson, L. R. (2007). The role of the family context in the development of emotion regulation. Social Development, 16, 361-388. https:// doi.org/10.1111/j.1467-9507.2007.00389.x.The.

*Murphy, T. P., Laible, D. J., Augustine, M., \& Robeson, L. (2015). Attachment's links with adolescents' social emotions: The roles of negative emotionality and emotion regulation. Journal of Genetic Psychology, 176, 315-329. https://doi.org/10.1080/ 00221325.2015.1072082.

*Nickerson, A. B., Mele, D., \& Princiotta, D. (2008). Attachment and empathy as predictors of roles as defenders or outsiders in bullying interactions. Journal of School Psychology, 46, 687-703. https://doi.org/10.1016/j.jsp.2008.06.002.

*O'Connor, T. G., \& Hirsch, N. (1999). Intra-individual differences and relationship-specificity of mentalising in early adolescence. Social Development, 8, 257-274. https://doi.org/10.1111/14679507.00094

*Oliva, A., Parra, Á., \& Reina, C. M. (2014). Personal and contextual factors related to internalizing problems during adolescence. Child Youth Care Forum, 43, 505-520. https://doi.org/10.1007/ s10566-014-9250-5.

*Overgaauw, S., Rieffe, C., Broekhof, E., Crone, E. A., \& Güroğlu, B. (2017). Assessing empathy across childhood and adolescence:
Validation of the Empathy Questionnaire for Children and Adolescents (EmQue-CA). Frontiers in Psychology, 8, 1-9. https:// doi.org/10.3389/fpsyg.2017.00870.

*Padilla-Walker, L. M., Christensen, K. J., \& Day, R. D. (2011). Proactive parenting practices during early adolescence: A cluster approach. Journal of Adolescence, 34, 203-214. https://doi.org/ 10.1016/j.adolescence.2010.05.008.

"Padilla-Walker, L. M., Dyer, W. J., Yorgason, J. B., Fraser, A. M., \& Coyne, S. M. (2015a). Adolescents' prosocial behavior toward family, friends, and strangers: A person-centered approach. Journal of Research on Adolescence, 25, 135-150. https://doi. org/10.1111/jora.12102.

*Padilla-Walker, L. M., Fraser, A. M., Black, B. B., \& Bean, R. A. (2015b). Associations between friendship, sympathy, and prosocial behavior toward friends. Journal of Research on Adolescence, 25, 28-35. https://doi.org/10.1111/jora.12108.

Piaget, J. (1965). The moral judgment of the child. Londen, England: Kegan Paul.

R Core Team. (2016). R: A language and environment for statistical computing. Vienna, Austria: R Foundation For Statistical Computing.

Rose, A. J. (2002). Co-rumination in the friendships of girls and boys. Child Development, 73, 1830-1843. https://doi.org/10.1111/ 1467-8624.00509.

Rose, A. J., \& Rudolph, K. D. (2006). A review of sex differences in peer relationship processes: Potential trade-offs for the emotional and behavioral development of girls and boys. Psychological Bulletin, 132, 98-131. https://doi.org/10.1037/0033-2909.132.1.98.

Rosenthal, R. (1979). The file drawer problem and tolerance for null results. Psychological Bulletin, 86, 638-641. https://doi.org/10. 1037/0033-2909.86.3.638.

Rosenthal, R. (1995). Writing meta-analytic reviews. Psychological Bulletin, 118(2), 183-192.

Selman, R. L. (1980). The growth of interpersonal understanding: Developmental and clinical analyses. New York, NY: New York Academic Press.

*Sillars, A., Koerner, A., \& Fitzpatrick, M. A. (2005). Communication and understanding in parent-adolescent relationships. Human Communication Research, 31, 102-128. https://doi.org/10.1093/ her/31.1.102.

*Siu, A. M., \& Shek, D. T. L. (2005). Relations between social problem solving and indicators of interpersonal and family wellbeing among chinese adolescents in Hong Kong. Social Indicators Research, 71, 517-539. https://doi.org/10.1007/s11205-0048034-y.

Smetana, J. G., Campione-Barr, N., \& Metzger, A. (2006). Adolescent development in interpersonal and societal contexts. Annual Review of Psychology, 57, 255-284. https://doi.org/10.1146/a nnurev.psych.57.102904.190124.

"Smith, R. L., \& Rose, A. J. (2011). The "cost of caring" in youths' friendships: Considering associations among social perspective taking, co-rumination, and empathetic distress. Developmental Psychology, 47, 1792-1803. https://doi.org/10.1037/a0025309.

"Soenens, B., Duriez, B., Vansteenkiste, M., \& Goossens, L. (2007). The intergenerational transmission of empathy-related responding in adolescence: The role of maternal support. Personality and Social Psychology Bulletin, 33, 299-311. https://doi.org/10.1177/ 0146167206296300.

*Stevens, D. L., \& Hardy, S. A. (2011). Individual, family, and peer predictors of violence among Samoan adolescents. Youth and Society, 45, 428-449. https://doi.org/10.1177/0044118X11424756.

*Telef, B. B., \& Furlong, M. J. (2017). Social and emotional psychological factors associated with subjective well-being: A comparison of Turkish and California adolescents. CrossCultural Research: The Journal of Comparative Social Science, 51, 491-520. https://doi.org/10.1177/1069397117694815. 
*Thompson, K. L., \& Gullone, E. (2008). Prosocial and antisocial behaviors in adolescents: An investigation into associations with attachment and empathy. Anthrozoos: A Multidisciplinary Journal of The Interactions of People and Animals, 21, 123-137. https://doi.org/10.2752/175303708X305774.

Van den Noortgate, W., López-López, J. A., Marín-Martínez, F., \& Sánchez-Meca, J. (2015). Meta-analysis of multiple outcomes: A multilevel approach. Behavior Research Methods, 47, 12741294. https://doi.org/10.3758/s13428-014-0527-2.

Van der Graaff, J., Branje, S., De Wied, M., Hawk, S., Van Lier, P., \& Meeus, W. (2014). Perspective taking and empathic concern in adolescence: Gender differences in developmental changes. Developmental Psychology, 50, 881-888. https://doi.org/10. 1037/a0034325.

*Van der Graaff, J., Branje, S., De Wied, M., \& Meeus, W. (2012). The moderating role of empathy in the association between parental support and adolescent aggressive and delinquent behavior. Aggressive Behavior, 38, 368-377. https://doi.org/10.1002/ab. 21435.

Van der Graaff, J., Carlo, G., Crocetti, E., Koot, H. M., \& Branje, S. (2018). Prosocial behavior in adolescence: gender differences in development and links with empathy. Journal of Youth and Adolescence, 47, 1086-1099. https://doi.org/10.1007/s10964017-0786-1.

*Van der Graaff, J., Meeus, W., de Wied, M., van Boxtel, A., van Lier, P., \& Branje, S. (2016). Respiratory sinus arrhythmia moderates the relation between parent-adolescent relationship quality and adolescents' social adjustment. Journal of Abnormal Child Psychology, 44, 269-281. https://doi.org/10.1007/s10802-015-9989-7.

Van der Mark, I. L., Van IJzendoorn, M. H., \& Bakermans-Kranenburg, M. J. (2002). Development of empathy in girls during the second year of life: Associations with parenting, attachment, and temperament. Review of Social Development, 11, 451-468. https://doi.org/10.1111/1467-9507.00210.

*Van Lissa, C. J., Hawk, S. T., Branje, S. J. T., Koot, H. M., Van Lier, P. A. C., \& Meeus, W. H. J. (2015). Divergence between adolescent and parental perceptions of conflict in relationship to adolescent empathy development. Journal of Youth and Adolescence, 44, 48-61. https://doi.org/10.1007/s10964-014-0152-5.

"Van Lissa, C. J., Hawk, S. T., Branje, S., Koot, H. M., \& Meeus, W. H. J. (2016). Common and unique associations of adolescents' affective and cognitive empathy development with conflict behavior towards parents. Journal of Adolescence, 47, 60-70. https://doi.org/10.1016/j.adolescence.2015.12.005.

Viechtbauer, W. (2010). Conducting meta-analyses in R with the metafor package. Journal of Statistical Software, 36(3), 1-48. https://doi.org/10.1103/PhysRevB.91.121108.

*Vieira, Jr., E. T. (2015). Family communication patterns, sympathy, perspective-taking, and girls' thoughts about interpersonal violence. Journal of Family Violence, 30, 607-619. https://doi.org/ 10.1007/s10896-015-9705-y.

*Winstanley, M. R., Meyers, S. A., \& Florsheim, P. (2002). Psychosocial correlates of intimacy achievement among adolescent fathers-to-be. Journal of Youth and Adolescence, 31, 91-100. https://doi.org/10.1023/A:1014093308760.

${ }^{*}$ Wu, C.-W., Guo, N.-W., Hsieh, Y.-S., \& Yeh, K.-H. (2015). The facilitating effect of need-supportive parenting on the change rate and adaptation of dual autonomy among Taiwanese adolescents. Swiss Journal of Psychology, 74, 181-195. https://doi.org/10. 1024/1421-0185/a000161.

Yeung, W. J., Sandberg, J. F., Davis-Kean, P. E., \& Hofferth, S. L. (2001). Children's time with fathers in intact families. Journal of Marriage and Family, 63, 136-154. https://doi.org/10.1111/j. 1741-3737.2001.00136.x.
*You, S., \& Kim, A. Y. (2016). Understanding aggression through attachment and social emotional competence in Korean middle school students. School Psychology International, 37, 255-270. https://doi.org/10.1177/0143034316631039.

*You, S., Lee, J., Lee, Y., \& Kim, A. Y. (2015). Bullying among Korean adolescents: The role of empathy and attachment. Psychology in the Schools, 52, 594-606. https://doi.org/10.1002/pits.21842.

Youniss, J. (1980). Parents and peers in social development: A Sullivan-Piaget perspective. Chicago, IL: The University of Chicago Press.

Youniss, J., \& Smollar, J. (1985). Adolescent relations with mothers, fathers, and friends. Chicago, IL: Chicago University of Chicago Press.

Zhang, S., Baams, L., van de Bongardt, D., \& Dubas, J. S. (2018). Intra-and inter-individual differences in adolescent depressive mood: The role of relationships with parents and friends. Journal of Abnormal Child Psychology, 46, 811-824. https://doi.org/10. 1007/s10802-017-0321-6.

*Zhang, W., Li, H., Gong, Y., \& Ungar, M. (2013). Stressful events and depression among Chinese adolescents: The mitigating role of protective factors. School Psychology International, 34, 501513. https://doi.org/10.1177/0143034312472760.

"Zhou, Q., Eisenberg, N., Losoya, S. H., Fabes, R. A., Reiser, M., Guthrie, I. K., \& Shepard, S. A. (2002). The relations of parental warmth and positive expressiveness to children's empathy-related responding and social functioning: A longitudinal study. Child Development, 73, 893-915. https://doi.org/10.1111/1467-8624. 00446.

Savannah Boele is PhD Student at the department of Developmental Psychology at Tilburg University in the Netherlands. Her research interests include the associations of parenting and parent-child and peer relationship quality with adolescent adaptation.

Jolien Van der Graaff is Assistant Professor at the Department Youth and Family at Utrecht University in the Netherlands. Her research focuses on the development of empathy and prosocial behavior in adolescence, as well as the associations with adolescents' relationships and social adjustment.

Minet de Wied is Assistant Professor at the Department of Youth and Family at Utrecht University in the Netherlands. Her current research interests include the development of empathy in healthy children and empathy problems in children and adolescents with disruptive behavior disorders.

Inge Van der Valk is Assistant Professor at the Department Youth and Family at Utrecht University in the Netherlands. Her research focuses on parental divorce in relation to child and adolescent adjustment.

Elisabetta Crocetti is Senior Assistant Professor at the Department of Psychology at Alma Mater Studiorum University of Bologna in Italy. Her major research interests include identity formation in adolescence and emerging adulthood.

Susan Branje is Professor at Utrecht University in the Netherlands. Her major research interests include understanding the developmental changes in adolescents' relationships with parents, siblings, friends, and romantic partners and the associations with development of adolescent personality, identity, and adjustment. 